\title{
MÚSICA Y FIESTA BARROCA: CELEBRACIONES EN TORTOSA EN HONOR DE FELIPE V $(1701)^{*}$
}

Marian Rosa Montagut

\begin{abstract}
This essay describes a specific case of the presence of music during the popular festivities that were held in Tortosa at the beginning of 1701 celebrating and exalting the coronation of the then new and recently crowned Monarch, the Bourbon Prince Felipe de Anjou. The source for analyzing the varied and abundant musical participation in the said festivities is a document printed in Barcelona in 1701 entitled "Festive merrymaking, courteous and loyal demonstrations with which the most faithful and exemplary city of Tortosa celebrated the joyous arrival in his Royal Court of our great Monarch, Felipe de Anjou (Bourbon), King of Spain (may God save him)". The importance of this anonymous document lies, on the one hand, in the detailed description it offers us of the essential role played by music - along with other artistic manifestations - in the majority of the activities, and, on the other hand, as a paradigmatic testimony of the relationship between music and "fiesta" during the epoch of the Hispanic Baroque.
\end{abstract}

\section{Resumen}

El presente trabajo se basa en un caso concreto de presencia musical en el contexto de unas celebraciones ciudadanas que tuvieron lugar en Tortosa, como festejo y propaganda política a favor de un nuevo y recién coronado monarca, a principios de 1701: el borbón Felipe de Anjou. El vehículo para analizar la variada y abundante participación musical de dichas festividades es un documento impreso en Barcelona en 1701, titulado "Alborozos festivos, leales obsequiosas demostraciones con que la fidelissima y exemplar ciudad de Tortosa celebró el feliz arribo a su real corte de nuestro gran monarca, y señor D. Felipe de Borbon rey de las Españas (que Dios guarde)". La importancia de este impreso anónimo radica, por un lado, en la detallada descripción que nos ofrece del papel primordial que desempeñó la música — junto con otras manifestaciones artísticas-en la mayor parte de los actos realizados ${ }^{1}$, y por otro lado, en ser un testimonio paradigmático de la relación entre música y fiesta en el barroco hispánico.

* El presente estudio ha sido posible gracias a una beca pre-doctoral de "Formació Investigadora" de la Generalitat de Catalunya para trabajar en el Departamento de Musicología (Institución "Milà i Fontanals") del CSIC en Barcelona. Agradezco al Dr. Antonio Ezquerro, director de mi tesis, la lectura y revisión del trabajo, así como a la Biblioteca de Catalunya $(E: B b c)$ las facilidades para consultar numerosa documentación y su permiso para reproducir algunas imágenes. Igualmente quiero dar las gracias a Enric Querol por darme noticia de la existencia del impreso sobre el que se basa la presente investigación.

1. Esta "detallada descripción" de la participación musical en las diferentes celebraciones realizadas, es una característica de este impreso que lo diferencia de muchos otros, dado que, como dice Louise K. STEIN ("Los músicos de la Capilla Real y la música de los festejos palaciegos, 1590-1648”, en La Capilla Real de los Austrias. Música y ritual de corte en la Europa moderna, Madrid, Fundación Carlos de Amberes, 2001, p.252), "leyendo las relaciones de las fiestas españolas, nos damos cuenta de que los organizadores y los participantes se concentraron en describir las excelencias de la presentación visual y social, no en la música ni en las canciones que formaban parte de ellas".

Anuario Musical, 59 (2004) 
Se ha escrito abundante a propósito de la denominada Guerra de Sucesión, acaecida a la muerte sin descendencia del último monarca de la dinastía habsbúrgica, el austria Carlos II, a finales de 1700. También muchos estudios históricos coinciden en que dicha guerra tuvo sus particularidades en el territorio catalán - muy especialmente en Barcelona-, posiblemente como consecuencia de que dicha zona, una vez planteados los condicionantes y situadas las posiciones de uno y otro bando (el del partidario borbón Felipe de Anjou, y el del pretendiente Carlos de Austria), se declaró abiertamente a favor del candidato que, a la postre, abandonaría el cetro español. Y todo ello, como es sabido, desembocó en los Decretos de Nueva Planta, con la dejación de los fueros y leyes propias catalanas en favor de una política centralizada desde la corte castellana, y las consiguientes represalias políticas para los territorios catalanes ${ }^{2}$.

En dicho contexto, la presencia musical que envolvió los fastos de la corte del que fuera proclamado como "Carlos III", residente un tiempo en Barcelona, así como las funciones festivas en favor de Felipe V (antes de desencadenarse la guerra, y después, una vez éste consolidó el trono), se ha estudiado, a menudo, a la luz de tópicos escasamente refrendados desde el punto de vista documental, muchas veces basados en acontecimientos históricos de concreción geográfica y temporal puntuales, y casi nunca estrictamente artísticos o musicales. Se daba en este sentido por hecho, que cuanto afectaba a la ciudad condal sucedía de igual modo - y casi a un tiempo- en el resto de Cataluña.

En este trabajo en cambio, se quiere llamar la atención sobre la "veleidad" de la política, y lo cambiante de la sociedad dado que, como sucediera en otros territorios de la península, respondía de algún modo a los cambios políticos y de gobernante en cada momento y lugar: ahora reinaba Felipe, se ensalzaba al rey; ahora se proclamaba Carlos, se cantaban sus glorias y alabanzas; y cuando cambiaba el signo político, éste parecía arrastrar consigo tanto a las masas como a las diversas autoridades locales, fueran concejos o cabildos eclesiásticos, que no dudaban en festejar alegremente al vencedor de cada momento, independientemente de cuáles fuesen sus verdaderas inclinaciones políticas personales — algo, en todo caso, difícil de rastrear-.

El vehículo elegido aquí para analizar la presencia musical en este tipo de celebraciones festivas es un interesante documento impreso por Rafael Figueró en Barcelona, en 1701, del que se conservan, al menos, dos ejemplares, uno en la barcelonesa Biblioteca de Catalunya ${ }^{3}$ y otro en el archivo de la Catedral de Tortosa ${ }^{4}$. Su título, como queda dicho, es: "Alborozos festivos, leales obsequiosas demostraciones con que la fidelissima y exemplar ciudad de Tortosa celebró el feliz arribo a su real corte de nuestro gran monarca y señor D. Felipe de Borbon rey de las españas (que Dios le guarde)”.

2. Véase: -Enrique BAyERrI y Bertomeu: Historia de Tortosa y su comarca, VIII. Tortosa, imprenta de Algueró y Baiges, 1959, pp.720-724; -VVAA: "Desfeta política i embranzida econòmica" Segle XVIII, en Història, Política, Societat $i$ Cultura dels Països Catalans. Barcelona, Enciclopèdia Catalana, 1995, vol.5, pp.138-174. -Pedro Voltes Bou: Catalunya i l'arxiduc Carles. Barcelona, Rafael Dalmau, 1999; -Josep M. Torras I Ribé: La guerra de Successió i els setges de Barcelona (1697-1714). Barcelona, Rafael Dalmau, 1999. -Glòria Ballús Casoliva: La música a la Colegiata Basílica de Santa Maria de la Seu de Manresa: 1714-1808. (Dades documentals per a la seva reconstrucció amb una aproximació al repertori litúrgic conservat). Tesis doctoral, Universitat Autònoma de Barcelona, 2004, pp.13-15 y 29-30.

3. $E$ : $B b c, \mathrm{FB} 9645$ (R.85501). [En todo el artículo utilizaré las siglas habituales del RISM (Répertoire International des Sources Musicales)].

4. E: $T O$, sin signatura.

Anuario Musical, 59 (2004) 
Su contenido nos relata las fiestas que entonces se realizaron en Tortosa, antes de que se configurara incluso el bando de los partidarios al pretendiente austríaco. El propósito de dichas fiestas que tuvieron lugar entre finales del mes de abril y los primeros días de mayo de 1701, era celebrar "el feliz arribo a sus reinos de Don Felipe V de Castilla y IV de Aragón”, así como "exaltar el Real Trono de las Españas".

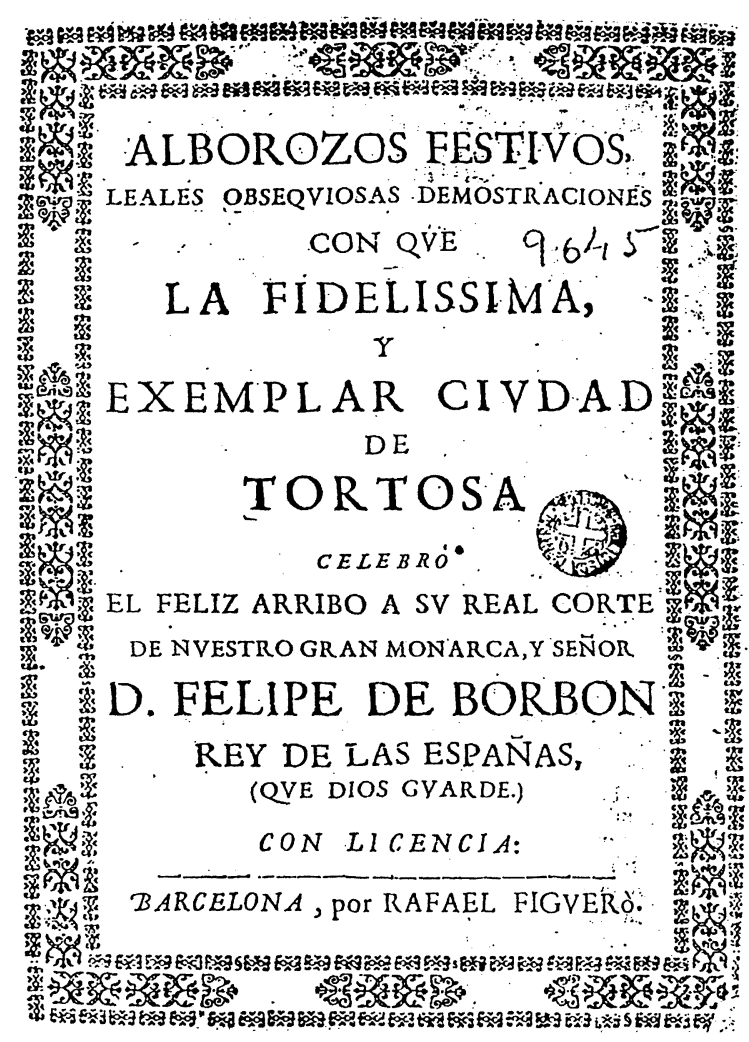

Fig.1.

$E$ : $B b c, \mathrm{FB} 9645$ (R.85501): Portada

Pero analicemos previa y brevemente la situación de principios de siglo, así como el contexto en el que se celebraron dichas festividades. Para empezar, hay que tener en cuenta que la inestabilidad política que afectó al territorio hispánico y a Cataluña desde los inicios del siglo XVIII y que se mantuvo, prácticamente, a lo largo de toda la primera mitad del mismo, repercutió directamente en las capillas de música y, por lo tanto, en los músicos. El 1 de noviembre del año 1700 fue la fecha que marcó el inicio de las futuras inestabilidades políticas del territorio hispánico, por ser ése el día en que muere Carlos II de Habsburgo después de, en última instancia, haber testado a favor de Felipe de Borbón (duque de Anjou, nieto de Luis XIV de Francia y futuro rey Felipe V de España).

En febrero de 1701, Felipe de Borbón es nombrado rey de Castilla (con el nombre de Felipe V) en las Cortes de Madrid y, en octubre, jura las constituciones catalanas e inicia las cortes en Barcelo- 
na. Como consecuencia de todos estos rápidos acontecimientos - y aunque a principios de 1701 todavía no se manifestaban explícitamente las disputas que muy pronto conducirían a la guerra de sucesión-, ya se empieza a sentir una tensión latente y a configurar el bando de los "austriacistas", aunque no está claro si, para entonces, dicha tensión ya se sentía realmente o no, en Tortosa ${ }^{5}$.

El caso es que, sea cierto o no que Tortosa sintiese una especial inclinación por el ya coronado Felipe V (así lo sugiere al menos el impreso en cuestión), en este estudio se pretende recalcar que el hecho de realizar diferentes manifestaciones festivas y/o composiciones musicales en favor de un monarca en la época, no debía implicar necesariamente, en todos los casos, estar realmente a favor del mismo, sino que, en ocasiones, podía esconder un cierto interés por contemporizar, de la mejor manera posible, con la inestabilidad política del momento: en el caso concreto de los músicos, bien es sabido que algunos de los que manifestaron abiertamente su preferencia por un monarca fueron despedidos en el momento de recuperar el poder el pretendiente contrario y, en el caso de las ciudades, resulta lógico que éstas intentasen conservar al máximo sus privilegios, evitando así, posibles represalias a posteriori.

De este modo, la situación descrita llevó consigo en numerosas ocasiones durante la guerra de sucesión, por un lado, que las autoridades locales - tanto civiles como eclesiásticas - promovieran festejos públicos diversos con la finalidad de ganarse las simpatías y el favor del monarca "de turno" $y$, por otro lado, el hecho de que los mismos músicos (bien en el contexto de estos festejos - como encargo de los concejos, cabildos u otras instituciones ${ }^{6}-$, bien inducidos por la situación política o bien "motu proprio" por sus simpatías ideológicas) realizasen algunas de sus composiciones con motivo de dichos festejos o de otros acontecimientos relacionados con el monarca del momento, esto es, bien del archiduque Carlos, bien de Felipe V, e incluso, alternativamente, de ambos. Veamos, respecto a este último punto, algunos ejemplos concretos cercanos a Tortosa:

- Entre las composiciones de Francesc Valls $(* 1671 c ; \dagger 1747)$, por entonces maestro de capilla de la Catedral de Barcelona, podemos encontrar villancicos en honor a ambos monarcas, aun cuando la mayoría de sus estudiosos coinciden en su inclinación "austriacista" como así parecen confirmarlo algunos de sus datos biográficos?

Al margen de cuáles fuesen sus inclinaciones ideológicas, el hecho es que, en cierto momento y circunstancias, Valls compuso música en honor de Felipe V, como son los casos siguientes:

Tres "VILLANCICOS, / QUE SE CANTARON EN LA SOLEMNE FIESTA, / que celebrò la Excelentissima Ciudad de Barcelona en la / Iglesia Cathedral, en los dias 10. y 11. de Março 1701. en /

5. Las festividades tortosinas en favor de Felipe se realizaron en abril, mientras que hasta septiembre de 1701 no se iniciaron las revueltas austriacistas (en pro del pretendiente Carlos) por diferentes lugares de Cataluña, entre los que se encuentran algunos territorios de Tarragona. Por cuanto se ha podido averiguar a partir de la bibliografía histórica consultada, no se explicita lo que sucede en cuanto a dichas revueltas en el caso concreto de Tortosa. [Véase: -Enric BAYERRI : Historia de Tortosa y su comarca. Tomo 8. Tortosa, imprenta de Algueró y Baiges, 1957; -Daniel Fernández Domingo: Anales o historia de Tortosa. Tortosa, Biblioteca Ebrenca, 1997; -Enric Querol Coll: Tortosa, república literària (1475-1800). Catàleg bibliogràfic d'escriptors i obres anònimes. Tortosa, Consell Comarcal del Baix Ebre, 1999. -Id.: "«La consolació corporal i temporal del poble»: pervivència del teatre a la ciutat de Tortosa en els segles XVI-XVIII" en El teatre català dels orígens al segle XVIII. Actes del II Col.loqui Problemes i Mètodes de Literatura Catalana Antiga «Teatre català antic». Girona, 6 al 9 de juliol 1998. Kassel, Reichenberger, 2001.

6. Entiéndase, naturalmente, que en la época - salvo raras excepciones - la mayoría de los músicos actuaban como meros asalariados y, en ese sentido, eran utilizados como "herramientas" por parte de sus mecenas — cabildos eclesiásticos, concejos, etc.- quienes, finalmente, eran los que adoptaban las decisiones y posturas políticas correspondientes, las cuales, obviamente, han quedado reflejadas en las composiciones musicales conservadas hasta nuestros días.

7. Veáse: -Josep Pavia I Simó: La música en Catalunya en el siglo XVIII. Francesc Valls (1671c.-1747). Barcelona, CSIC, 1997. 
Música y fiesta barroca: celebraciones en Tortosa en honor de Felipe V (170i)

accion de Gracias à su Divina Magestad, por el feliz arribo / del Rey nuestro Señor Don FELIPE QVINTO (que Dios / guarde) à su Real Corte de Madrid; y para impetrar de / la Divina Magestad sus felizes aciertos, y / dilatados años de vida"8. [Véanse Figs. 2a y 2b]

Y otros tres "VILLANCICOS, / QUE SE CANTARON EN LA SOLEMNE FIESTA, / que celebrò la Deputacion del Principado de Cathaluña en / su Capilla grande de San Jorge, en los dias 12. y 13. de Março / 1701. en accion de Gracias a su Divina Magestad, por la / sucesion, y feliz arribo del Rey nuestro Señor Don FELIPE / Quarto en Aragon, y Quinto en Castilla, Conde de Barcelona / (que Dios guarde) à los Dominios de España, y su Real Corte / de Madrid". [Véanse Figs. 3a y 3b]

En el caso de estos textos de villancicos recogidos en impresos de 1701, puede observarse que el correspondiente a la fig. 3 coincide con el villancico a 14 a N[uestr]a S[eño]ra "Brillantes escuadras" de Valls. Las modificaciones del texto original —repárese, en la parte de Tenor, cómo se ha tachado la significativa palabra del texto, "Cataluña" (de: "... feliz Cataluña tus glorias publica"), y se ha sustituido por "todo el orbe" (para decir, así: “... feliz todo el orbe tus glorias publica")— - se hicieron, sin duda, para aprovechar la pieza para alguna festividad mariana, como sugieren algunos papeles musicales en que se anotan coplas alternativas "A M[arí]a S[an]t[ísim]a", así como la portada donde se anota "A N[uestr]a S[eño]ra". [Véanse Figs. 4a y 4b]

Los ejemplos expuestos, por otra parte, nos corroboran que las festividades celebradas en Tortosa - diez días- en honor a Felipe $\mathrm{V}$ tras su coronación (y algo más de un mes después que en Barcelona, donde apenas se celebraron durante unos pocos días y en lugares distintos), no fueron, ni mucho menos, unas celebraciones aisladas, del mismo modo que tampoco lo fue el hecho de que el maestro de capilla de la ciudad en cuestión (Barcelona, Tortosa, Gerona...), tal y como era su obligación, compusiese música para el especial evento, al margen de cuál fuese su propia ideología ${ }^{10}$.

En todo caso, Valls compuso en muchas más ocasiones, por cuanto sabemos hasta el momento, en honor de Carlos III, sobre todo durante los años en que este estableció su corte en Barcelona, como es el caso siguiente:

Tres "VILLANCICOS, / QUE SE CANTARON EN LA FIESTA, QUE EL / Ilustrissimo y Fidelissimo Consistorio de la Diputacion consagrò / à su Invictissimo Patron el Cavallero, y Martyr SAN JORGE, / en demostracion de alegria, por el motivo de que la Magestad del Rey nuestro Señor / DON CARLOS III. / (que Dios guarde) / honra con su leal presencia à este Principado" ", que fueron interpretados por la capilla de música de la catedral de Barcelona el 15 de noviembre de 1705, con motivo de la entrada de Carlos en Barcelona, el día 7 del mismo mes. También, en esta ocasión, la ciudad celebró el evento con grandes festejos y solemnidades religiosas con abundante presencia musical, principalmente, con composiciones del maestro Valls. [Véase Fig. 5]

8. $E: B b c, \mathrm{FB} 9499$. [ $\mathrm{FB}=$ Fondo Bonsoms].

9. $E: B b c, \mathrm{FB} 9501$.

10. Resulta curioso que fuesen precisamente tres los villancicos compuestos por F. Valls con motivo de cada una de las celebraciones realizadas en Barcelona, la primera en la Catedral el 10 y el 11 de marzo de 1701 y la segunda en la capilla grande de San Jorge los días 12 y 13 de marzo del mismo año, y que también fuesen tres los villancicos que compuso Baltasar Sanz para las festividades celebradas en Tortosa por el mismo motivo, como más adelante se verá.

11. E: Bbc, FB 2960. Veánse también los siguientes textos de villancicos de Valls en E: Bbc: FB 5681 ("VILLANCICOS, / QUE SE CANTARON EN LA FIESTA, QUE LA / Excelentissima Ciudad de Barcelona consagra à Dios / Nuestro Señor, en Accion de Gracias, y demostracion de / la alegria, por ocasion de que la Magestad del Rey Nuestro / Señor Don CARLOS III. (que Dios guarde) honra / con su Real presencia à esta Ciudad; y se dedica el Sagrado / Culto à la Sacratissima Reyna de los Angeles. MARIA / Santissima Señora Nuestra el dia 8, de / Noviembre de 1705"), y FB 5682 (“VILLANCICOS, / QUE SE CANTARON EN LA FIESTA, QUE EL / Ilustrissimo y Fidelissimo Consistorio de la Diputacion consagrò / à su Invictissimo Patron el Cavallero, y Martyr SAN JORGE, / en demostracion de alegria, por el motivo de que la Magestad del Rey nuestro Señor / DON CARLOS III. / (que Dios guarde)/ honra con su leal presencia à este Principado"). 


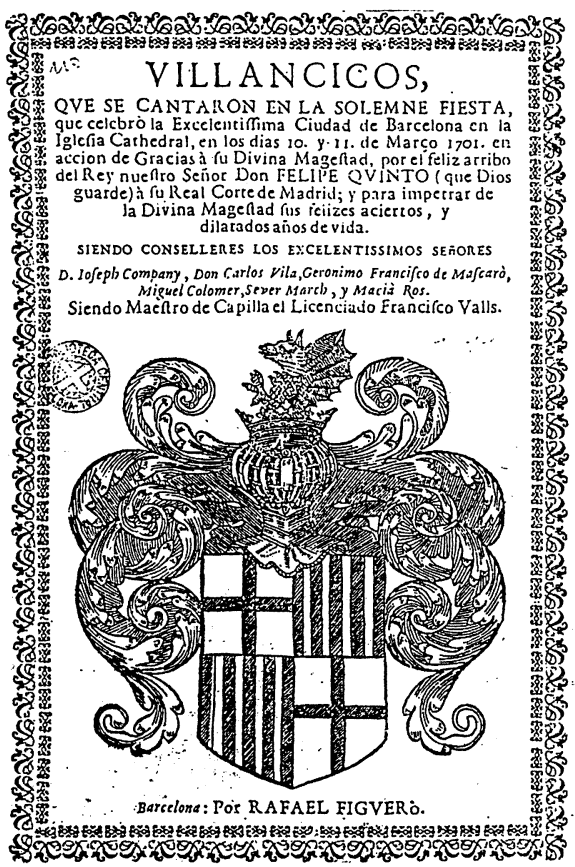

Fig. 2a

$E: B b c$, FB 9499

a) Portada
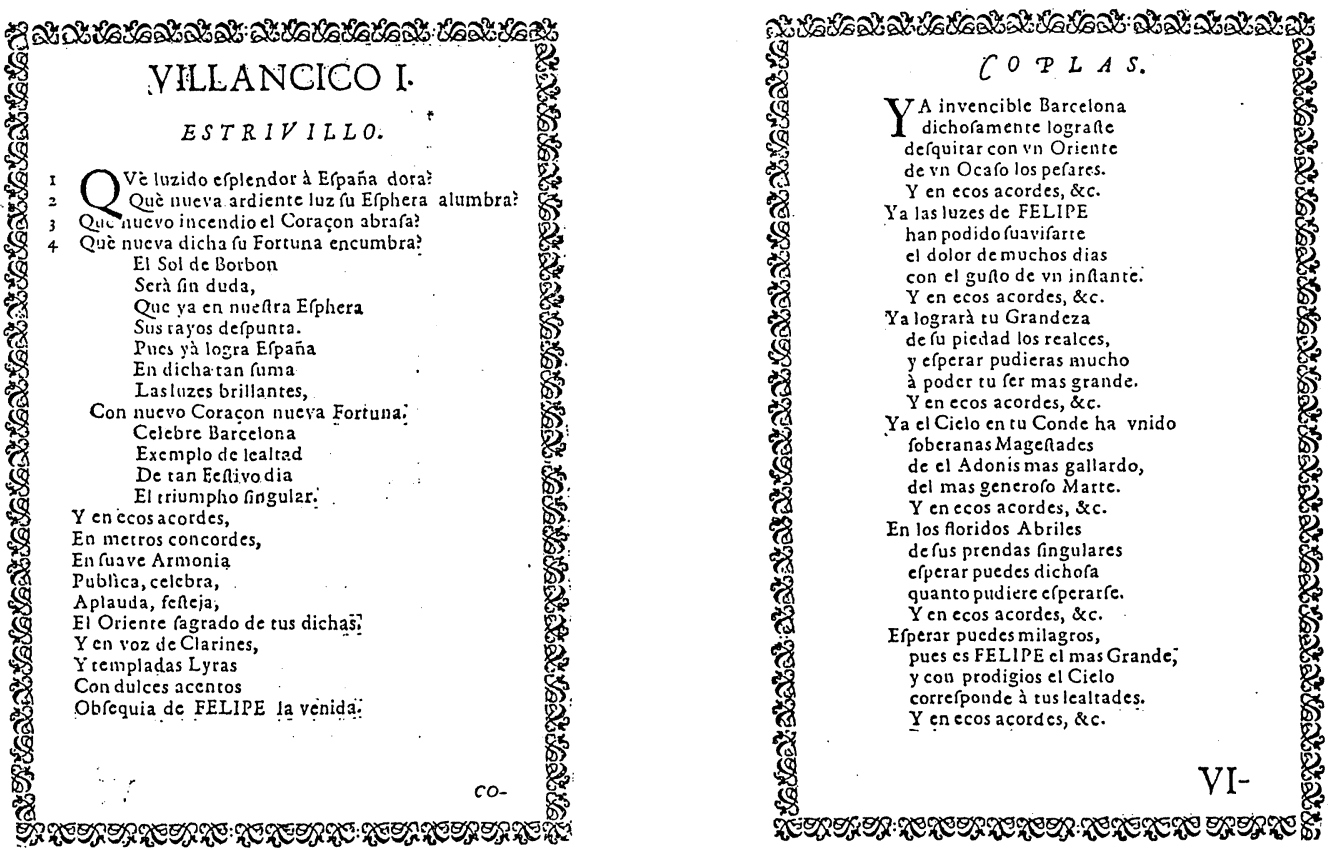

Fig. 2b

$E: B b c, \mathrm{FB} 9499: b$ ) Texto del primer villancico. 


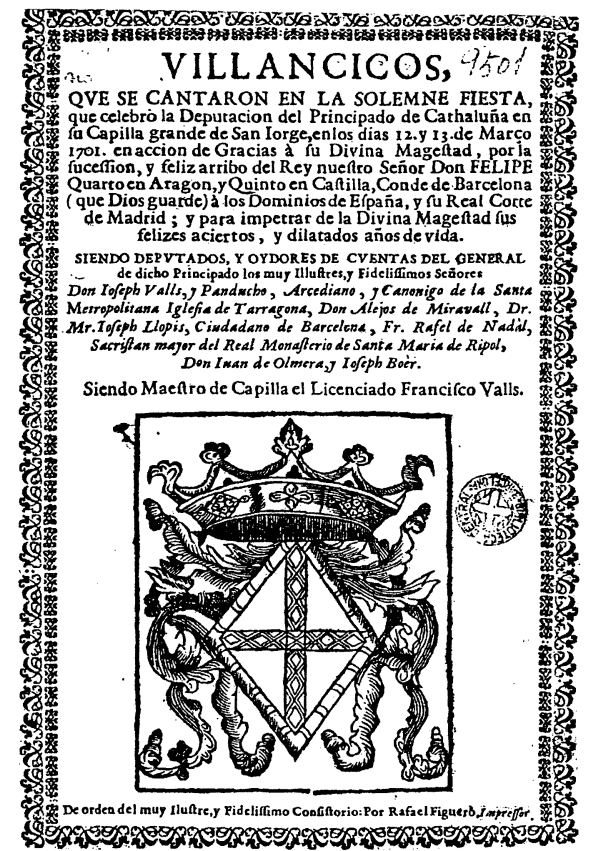

Fig. 3a

$E: B b c, \mathrm{FB} 9501:$

a) Portada
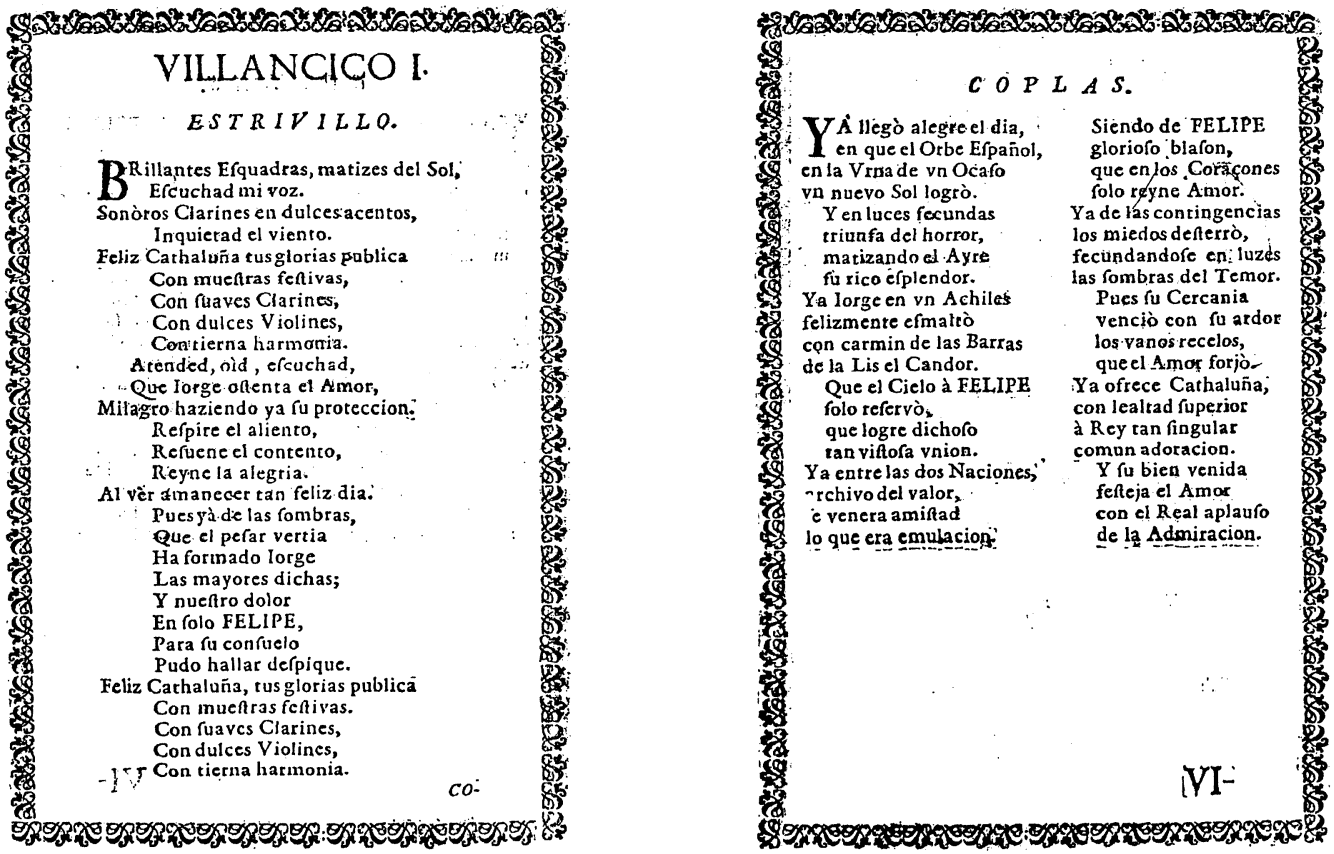

Fig. 3b

$E: B b c$, FB 9501: b) Texto del primer villancico 


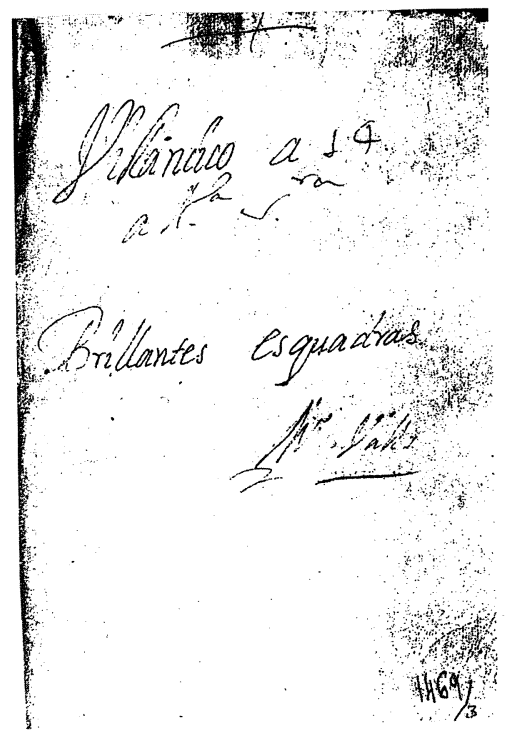

Fig. 4a

$E$ : Bbc, M.1469/3. Francesc Valls. Manuscrito con la música:

a) Portada - vuelto del "Aco. ${ }^{\text {to }}$ Continuo"-

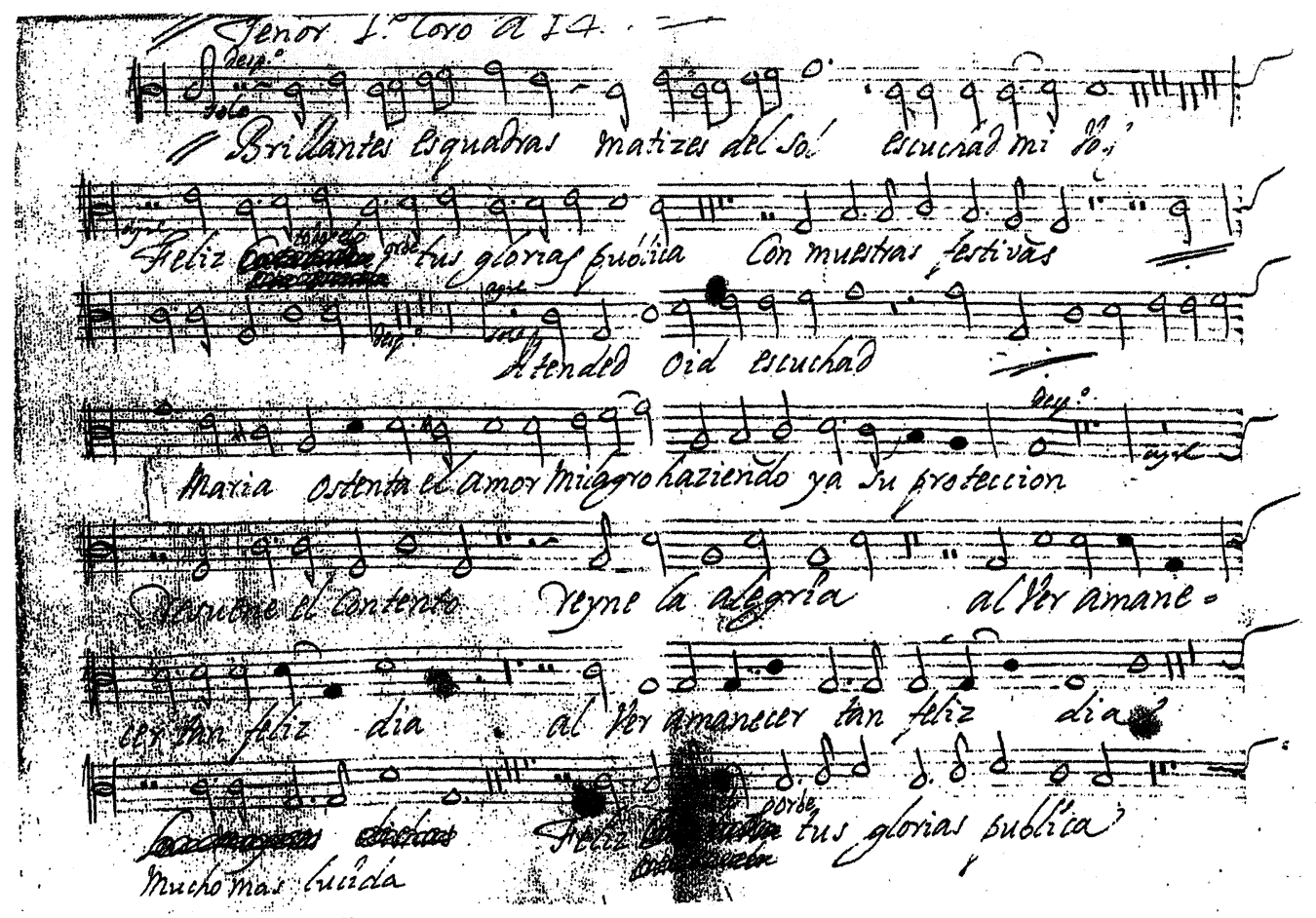

Fig. 4b

$E: B b c$, M.1469/3. Francesc Valls. Manuscrito con la música:

b) Parte del "Tenor $1^{\circ}$ Coro" ["Estrivillo", a 14]. 


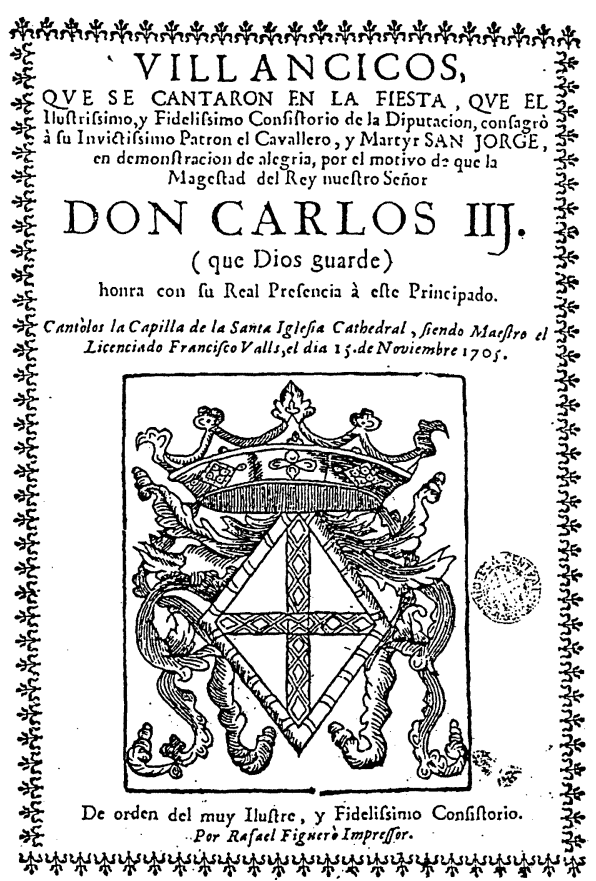

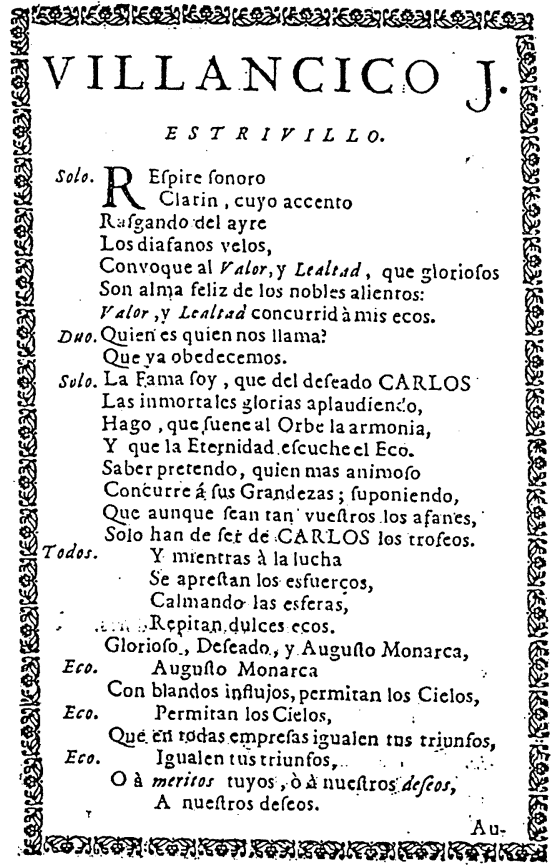

Fig. 5.

Contamos asimismo con el villancico a 7 "Ya Tortosa ilustre" del maestro de capilla —primero de Tarragona y posteriormente de Tortosa- Josep Escorihuela $(* 1674 ; \uparrow 1742)$ dedicado a Carlos III que muy probablemente habría que datar entre marzo y julio de 1708 , copiado en el manuscrito actualmente conservado en la biblioteca de la Universidad de Cracovia (PL-KJ, Mus.ms.40317) ${ }^{13}$, fols.169r-172r.

12. Repárese en el escudo que inserta el impresor, el mismo que en la Fig.3a, en ese caso para Felipe V, y aquí para Carlos III.

13. Dicho manuscrito fue copiado por el contralto (en 1704) y maestro de capilla (desde 1708) de la Catedral de Tarragona Crisóstomo Ripollés. El manuscrito en cuestión fue comenzado a copiar en 1704 y, al parecer, terminado en 1711, ocupando el villancico "Ya Tortosa ylustre" el lugar $n^{\circ} 60$ del mismo. Sin embargo, dado que Josep Escorihuela ocupó el magisterio de la Catedral de Tortosa el 10 de marzo de 1708, cabe pensar que el citado villancico en honor a Carlos III habría que datarlo entre dicha fecha y poco antes de que Felipe V recuperase el control de dicha ciudad — previamente pro-austriacista-, el 10 de julio del mismo año (es decir, que dataría muy posiblemente del año 1708 - entre marzo y julio-). [Véanse: -Relacion de las expressiones de aprecio hizo Cathaluña en la vuelta de su adorado, y catolico monarca Carlos Tercero (que Dios guarde) hasta la ostentosa Militar Entrada de Barcelona, que fue á 22. de Março 1707. Barcelona, Rafael Figuerò impresor, 1707; -Josep Maria GREGORI I CIFRÉ: "Joan Crisòstom Ripollès (+1746): Biografia i catalogació de la producció musical conservada", en Boletín Arqueológico, IV (19761977), pp.133-140. -ID.: "Joan Crisòstom Ripollès (ca.1680-1746), mestre de capella de la catedral de Tarragona", en Recerca Musicològica, II (1982), pp.19-41. -ID.: "Joan Crisòstom Ripollès (1678-1746) a les oposicions del magisteri de capella de la Seu de Tortosa del 1708", en Butlletí Arqueològic, V (1992), pp.137-147. -ID.: "La música a la catedral de Tortosa a principis del segle XVIII: el memorial de l'organista Tomàs Serrano", en Recerca Musicològica, XIII (1998), pp.63-76. -Josep PA VIA I SIMó: La música en Cataluña en el siglo XVIII. Francesc Valls (167l c-1747). Barcelona, CSIC, Institució "Milà i Fontanals", 1997, pp.309 y 311; -Francesc Bonastre i Bertran: "Escorihuela. 2. Escorihuela, Josep", en Diccionario de música española e hispanoamericana, vol. 4, Madrid, SGAE, 1999, p.732. Agradezco asimismo algunas informaciones al respecto facilitadas por Francisco Javier RomEro NARANJo en su comunicación "Fuentes musicales españolas en Cracovia. El libro de música de Chrisóstomo Ripollés", presentada en el congreso "Miguel Querol y la música hispánica del barroco", Barcelona, CSIC, febrero de 2004]. 


\section{Estribillo}

Viva nuestro Carlos, viva nuestro rey, viva nuestra reina, viva nuestro rey. Viva nuestro Carlos, viva nuestro bien, viva nuestra reina, viva nuestro rey. ¿Qué es esto, dertusenses? ¿qué novedad es esta? ayer entre tan grandes aflicciones ayer librando Marte sus ardores, y hoy con tanto gusto y tanta fiesta.
Siendo gloria para Dios el que haya paz en la tierra, el que es rey de todo el mundo viene a desterrar la guerra y esto con tanta igualdad, que reparte a cada uno, sin dar ni quitar a nadie, todo lo que fuere suyo. Este el día de hoy el asunto, pues se ve esta catedral ilustre, esta ciudad siempre fiel, bajo el dominio de Carlos fuera del yugo cruel. ${ }^{14}$

En ese mismo manuscrito de Ripollés se conserva otra composición de Josep Escorihuela con claras referencias a Carlos III. Se trata del villancico a 9, "A la batalla naval" 15 :

\section{[Estribillo]}

Dos batallas, dos vitorias, tan iguales a mi ver que parecen una cosa a mi modo de entender. Fue la batalla naval la primera porque fue un austriaco lucero quien echó al turco al través.
Fue la segunda batalla la de Carlos pues se ve por ella ya coronado y Castilla cual la vez, ¡vitoria! una allá en Lepanto y otra acá en España.

$[\ldots]$

Aunque en ocasiones, la bibliografía disponible ha aludido al carácter austracista de J. Escorihuela, se conoce también una obra suya, en pro de Felipe $\mathbf{V}$, de la que, lamentablemente - a fecha de hoy-, no se ha podido localizar la fuente original. Sin embargo, ha quedado en el archivo de la Catedral de Tortosa, una transcripción manuscrita realizada por mosén Vicente García Julbe $(* 1930 ; \dagger 1997)$, quien fuera canónigo-prefecto de Música Sacra en dicha catedral; se trata del "Villancico a 11 con violines a Nuestro Monarca Rey de España El Sr. Dn Philipo Quinto, Joseph Escoriguela, 1719”.

14. A partir del texto de este villancico parece claro que, aunque este "Libro de Musica" del maestro C. Ripollés —que lo firma en Tarragona - se haya adscrito tradicionalmente a dicha capital catalana, supone no obstante una recopilación de fuentes de diversa procedencia. Una muestra de ello es la alusión, en este mismo texto, a los "dertusenses", claro síntoma, en una composición de J. Escorihuela, de que la obra iba destinada a la ciudad de Tortosa, y no a Tarragona. Por otro lado, el texto aquí insertado sugiere, que, si bien Tortosa celebró en 1701 "el feliz arribo a sus reinos de Don Felipe V de Castilla y IV de Aragón", unos años más tarde mostrará, al menos públicamente, el mismo entusiasmo por el archiduque Carlos, por librarles éste de las aflicciones y guerras del cruel "Marte" (el tan exaltado por la misma ciudad, unos años antes, Felipe V). En ambos casos, el maestro de capilla del momento fue el encargado de realizar ciertas composiciones para la ocasión, primero Baltasar Sanz y, después, Josep Escorihuela.

15. Manuscrito: Biblioteca de la Universidad de Cracovia (PL-KJ, mus.ms.40317), fol.181r-185v. [Este manuscrito fue conocido largo tiempo por su anterior conservación en la biblioteca real de Berlín]. Este villancico en concreto, a diferencia del anterior, no explicita su dedicación al archiduque Carlos — ni en el título, ni en su encabezamiento-, si bien ésta resulta evidente a partir de la lectura de su texto. 
Por su parte, el maestro de capilla de la Catedral de Gerona desde 1690, José Gaz, compuso, en honor del archiduque Carlos, Hoy que Gerona a María "consagra fiesta real en créditos de amor leal, será de Carlos el día” [Estribillo], “...y vos, Carlos III, para siempre vivid, que todos os veamos coronado en Madrid" [final de las coplas], con motivo de la visita oficial que el archiduque Carlos realizó a Gerona el 15 de enero de 1710;

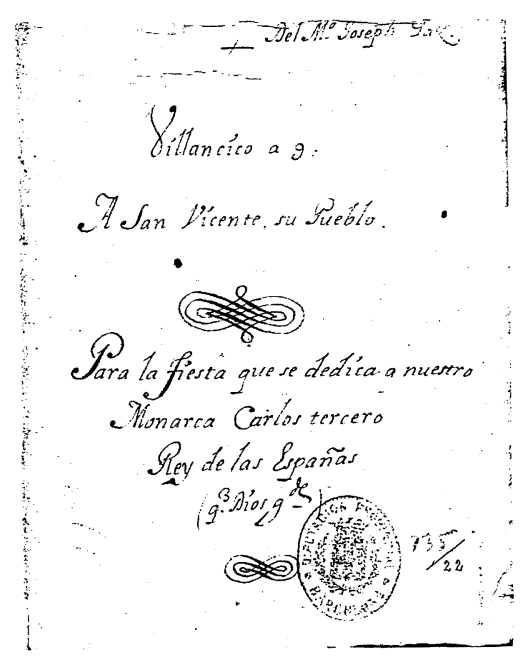

Fig. 6

$E: B b c$, M. 735/22 José Gaz. Manuscrito musical:

a) Portada

b) Tiple Coro $1^{\circ}$

(Introducción y comienzo del Estribillo)

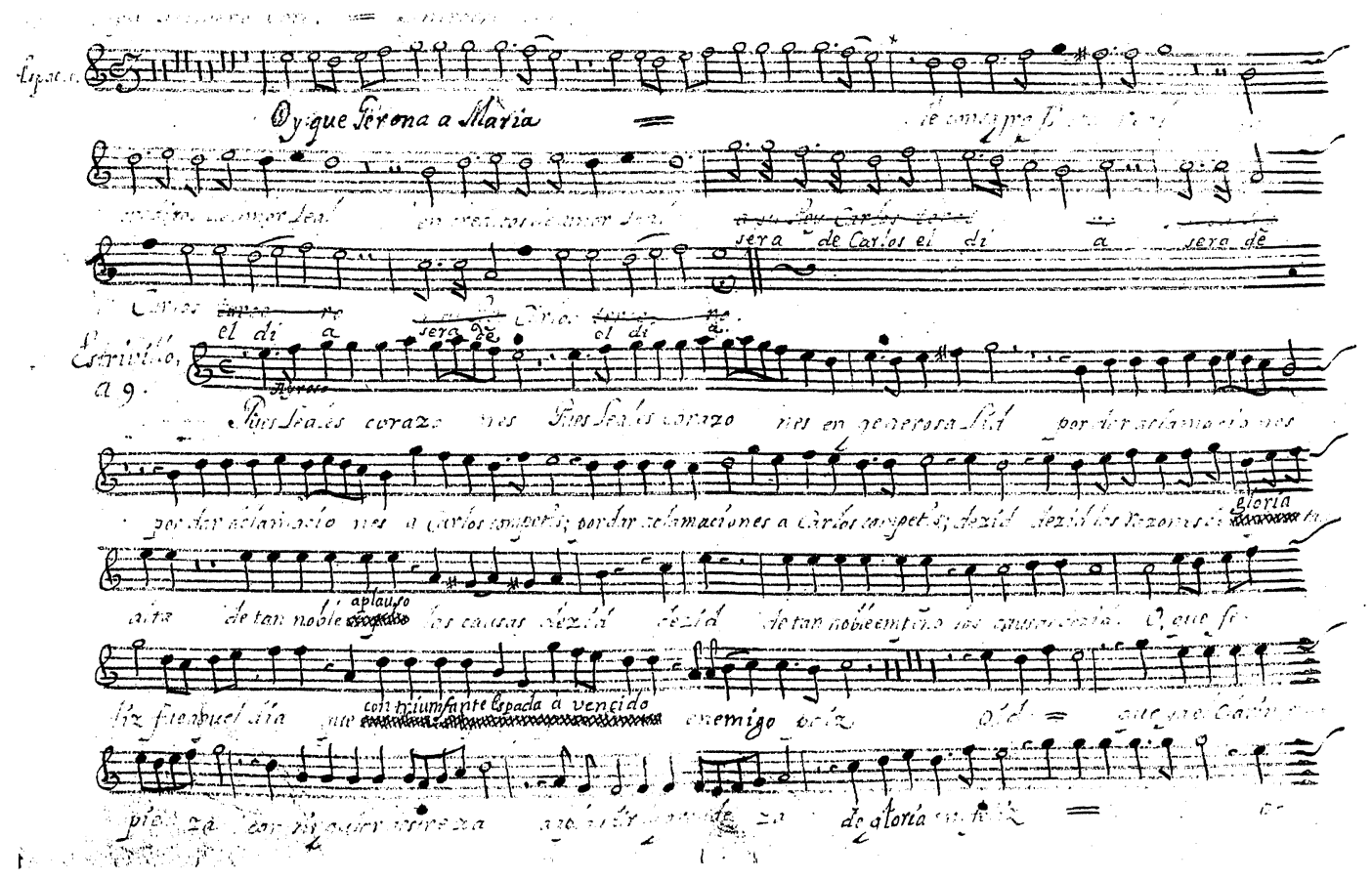


y en 1711, cuando Gerona pasó de nuevo a poder de Felipe $\mathrm{V}$ y el obispo partidario del borbón, Miguel Juan de Taverner, fue repuesto en su cargo, el mismo José Gaz también festejó el acontecimiento, en honor de Felipe V, dedicándole el villancico Venid mortales, "A la bienvenida del Ilmo. y Rmo. Sr. D. Miguel Juan de Taberner y Rubí, mi señor; dignísimo Obispo de Gerona, electo Arzobispo de Tarragona, por la magestad de Nuestro Rey y Señor Felipe V, Monarca de las Españas"16.

Vista pues, aunque brevemente, la situación política de principios del siglo XVIII, así como el papel que desempeñaron los maestros de capilla en la misma, se analizará a continuación, más detalladamente, la presencia y el importante papel que jugó la música en las festividades tortosinas descritas en el mencionado impreso de 1701, "Alborozos festivos, leales obsequiosas demostraciones...".

Según el impreso estudiado, el consejo general de la ciudad decide, el 28 de marzo de 1701, que el primer día de los festejos — de los diez que se celebrarán para dar gracias por la llegada a la corte madrileña del nuevo rey ${ }^{17}$, y para exaltar su advenimiento al trono "de las españas"18 — sea el representativo 23 de abril ("Sant Jordi"), aunque, en realidad, se realizaron ya diferentes manifestaciones festivas el día anterior, 22, como es el caso de las siguientes: a las 11 de la mañana, el capitán Sebastián Llabería y su compañía - de las Milicias de los naturales - salieron a las calles de Tortosa "al son de las Caxas" y los soldados dispararon incesantemente por las calles "repitiendo todos victores al grande Felipe nuestro rey"; a las 12 se oyeron las campanas, al mismo tiempo que sonaban chirimías, clarines y cajas, así como disparos de artillería, junto con voces de "viva el Rey"; en consecuencia, una confusión de campanas, tiros, instrumentos y vítores ${ }^{19}$.

16. No disponemos de la música ni del texto completo de dicho villancico a Felipe V; no obstante encontramos referencias a dicha obra en: -Felipe Pedrell: Catàlech de la Biblioteca Musical de la Diputació de Barcelona. Barcelona, Palau de la Diputació, 1909, vol.II, p.30; y en: -Antonio Martín Moreno: Historia de la música española. Siglo XVIII. Madrid, Alianza Música, 1985, vol.4, p.161.

17. Previamente al inicio de los festejos e incluso a la decisión de su realización, la llegada de una carta a Tortosa con la firma del Rey notificando su llegada a Madrid "con entera salud" fue celebrada por los ilustres Cabildo y Magistrado con un Te Deum que se cantó, en acción de gracias, en la catedral.

18. Lo entrecomillado procede del impreso mencionado.

19. Esta manifestación sonora es común a numerosas festividades barrocas en todo el ámbito hispánico -incluido Latinoamérica- [Véase: -Luis Antonio González Marín: "Fuentes y método para el estudio de la música de las fiestas en la Edad Moderna", en Metodología de la Investigación Científica sobre fuentes aragonesas. Zaragoza, Universidad de Zaragoza, ICE, 1993, vol.8, pp.201-214; -Id.: "La música y las fiestas en la Edad Moderna", en Fiestas públicas en Aragón en la Edad Moderna. Zaragoza, Diputación General de Aragón, 1995, pp.57-68]. Contamos asimismo con testimonios coetáneos en Italia: entre los numerosos documentos italianos que hacen referencia a este conjunto sonoro en la época (Niza, 1641; Venecia, 1681; Bologna, 1685; Roma, 1693 y 1697; etc.), encontramos uno de especial relevancia para nuestro caso, dado que se trata, como en el impreso tortosino estudiado, de unas festividades celebradas en Roma en 1701 en honor a Felipe V. [Véase: -Gino Stefani: "La Festa", en Musica barocca. Poetica e ideologia. Milano, Bompiani, 1987, pp.9-72]. Por otra parte, en cuanto al significado de esta manifestación sonora - campanas, instrumentos, voces y disparos al mismo tiempo-, encuentro muy acertada la opinión de Stefani en su consideración del aplauso como máxima intensidad expresiva de todo el ambiente festivo. Justamente, el disparo de la artillería constituye, de este modo, la expresión sintética del aplauso, el cual puede acompañarse, como sucede en nuestro caso concreto de Tortosa - y en muchos otros-, con campanas, tambores, voces, instrumentos, etc. Esta masa sonora, como signo del aplauso, refleja todo el carácter de la fiesta: la guerra, el juego, el arte, la religión, etc. [-Ibid., pp.16-18].

Anuario Musical, 59 (2004) 
Esta celebración sonora, llevada a cabo por diferentes lugares de la ciudad, se mezclaba, además, con la estimulación de otros sentidos, como el visual y el olfativo ${ }^{20}$, dado que el consejo mandó que ardiesen todas las noches luminarias — hachas y todo género de luces posibles - en las calles y balcones de las casas de los señores más ilustres, y el cabildo mandó hacer lo mismo a los capitulares, alrededor de la catedral y de las demás iglesias de la ciudad, con faroles y otras "invenciones de fuego".

Esta pretensión de simular el día incluso de noche, con tal cantidad de luminarias ("y al fin toda Tortosa se vio arder, nueva Troya"), duró tres días y fue acompañada, como no podía ser menos, de la correspondiente estimulación auditiva, ya que el consejo también mandó que se tocaran las chirimías y otros instrumentos, tanto de cuerda como de viento, acompañados de cajas y clarines, por diferentes lugares de la ciudad, y el cabildo decidió que al mediodía y a las oraciones, todos los conventos, parroquias e iglesias, hiciesen "volar" sus campanas al mismo tiempo que las de la catedral y a la vez que, en ésta, se tocaban chirimías y se disparaban gran cantidad de morteretes ${ }^{21}$, durante los mismos tres días de las luminarias.

El día oficialmente establecido como el primero de las celebraciones, el sábado 23 de abril, fue el elegido por el cabildo catedralicio para tomar la fiesta a su cargo y, en cuanto a la presencia musical, resulta ser uno de los más significativos, por varias razones.

En primer lugar, dicho día se celebró un Oficio "con la solemnidad [que] se acostumbra en esta Santa Iglesia [catedral], y en que ninguna de las de la Corona [de Aragón] la aventaja" y tras él, "cantò la Missa el Ilustre Señor D. Sebastian Iordá, y la Torre Prior Clauster, Pabordre, y Canonigo de la S. Iglesia de Tortosa" en la cual, "después de la Epistola cantò la Capilla un Villancico hecho al caso, las vozes dulces, sonoras las consonancias, la composicion de el Licenciado Baltazar Sans ${ }^{22}$ Racio-

20. Una de las características fundamentales de la fiesta barroca hispánica —que también encontramos en Italia- es que nos ofrece una articulación integrada de todos los sentidos, en tanto que manifiesta, al menos, la estimulación visual, olfativa y auditiva (música, luminarias, flores, poesía, teatro, bailes, etc.). Y como curiosidad - y acaso la especificidad menos tratada del conjunto-, conviene incidir en el hecho de que este tipo de "fiesta integral" aunaba tanto la celebración civil, como incluso la militar, y la religiosa. De este modo, el aspecto puramente olfativo del "espectáculo" en su conjunto, se traduciría no sólo en la profusión del engalanamiento ciudadano con flores (asimismo con su consecuente estimulación visual), sino también en el casi constante olor a pólvora (salvas de artillería, tracas y fuegos artificiales, también con un importante componente auditivo), incienso y cera quemada (en el ámbito concreto del templo), o antorchas y leña prendida (para las luminarias o como simples hogueras)... [Sobre este tema, véase también: -Gino Stefani: Id. pp.9-72; -Carlos SeOAne y Andrés Eichmann Lírica Colonial Boliviana, Bolivia, Quipus, 1993, pp.42-47; -José María DíEz Borque "De los siglos de oro al siglo de las luces" en: -Andrés Amorós y José María DíEz, coord. Historia de los espactáculos en España pp.207-238. Madrid, Castalia, 1999].

21. Piezas pequeñas de artillería (morteros pequeños) que se utilizaban frecuentemente en las salvas.

22. Por lo que he podido averiguar a partir de la bibliografía disponible, Baltasar Sanz ha sido un músico, hasta la fecha, poco estudiado y del que apenas existen algunas noticias dispersas y confusas. Según Francesc Bonastre ["Nota biogràfica: Baltasar Sanz", en Recerca Musicològica, VIII (1988), pp.139-141], el aragonés Baltasar Sanz nació en la localidad zaragozana de Brea alrededor de 1650 y se formó como infante en la escolanía de La Seo de Zaragoza. Esta información despista un poco, por cuanto, consultadas las actas capitulares de ambas catedrales zaragozanas (El Pilar, y La Seo, respectivamente), nos dan las siguientes noticias, siempre referidas a El Pilar, y nunca a La Seo: hubo, en la década de 1660, diversos "infanticos" —al menos dos y muy posiblemente alguno más - procedentes de la localidad de Brea, algunos de ellos, incluso, que llegaron a realizar estudios de maestro de capilla. Normalmente, no se aportan sus nombres concretos (vid. -José V. GonZÁlEZ VALlE et al.: "Regesta de noticias referentes a la música en las actas capitulares del Pilar (1656-1676)", en Aragonia Sacra, I (1986), pp.187-195 - véase concretamente p.190-). Así, el primer "infante Brea" de que tenemos constancia, participa como cantor Tiple en un villancico del maestro de capilla de El Pilar, Miguel Juan Marqués, en el año 1656 (véase: -Antonio EzQUERro: Villancicos policorales aragoneses del siglo XVII. Barcelona, CSIC, 2000, p.221 - cfr. incipits musicales-). Dando por buenas las informaciones de F. Bonastre, éste podría haber sido nuestro protagonista, caso de haber nacido un par o tres de años antes de $1650 \ldots$, en cuyo caso tendría en 1656 ocho o 
nero, y Maestro de Capilla bastantemente conocido por sus obras, y su ingenio ${ }^{23}$, y es lo mas tener tan buen juizio, quien es gran Poeta, y gran Musico". Tras cantarse el evangelio y predicarse el sermón, se prosiguió con la misa y "se cantaron otros villancicos, y se dio fin a la fiesta de la mañana". Por el momento no he podido localizar la música de ninguno de los villancicos hechos para el caso aunque, por otro lado, resulta interesante la información ofrecida en relación a la cantidad y el momento en que se interpretaban los mismos dentro de las celebraciones litúrgicas, esto es, uno en la misa tras la epístola, y varios al terminar la misma, más o menos como "final de fiesta".

Siguiendo el Cabildo con las celebraciones, por la tarde se cantaron unas vísperas y "estrenò nueva Musica la Capilla, cantò el Coro las Completas, y se hizo una Procession General en accion de gracias. Ivan delante algunas Dulçaynas ${ }^{24}$, y Caxas, los Gigantes, la Tarasca (llamada acà Cucafera) [...]", detrás iban las Cofradías y sus miembros con velas encendidas, las Banderas "ricas todas de damasco de varios colores, con escudos bordados de oro", la Cruz de la Catedral, las muchas comunidades de religiosos/as de la ciudad (Capuchinos, Carmelitas descalzos, Trinitarios, etc.) y, tras ellos, las numerosas comunidades de beneficiados y racioneros de la Catedral, así como el Cabildo y otras "Ilustres Dignidades" y, en un adornadísimo Trono, la "preciosa Reliquia de la Santa Cinta"25, etc.; es

nueve años. Más tarde, encontramos a un "Infante Mayor de Brea", a quien se propone despedir por no acudir a coro y a sus obligaciones el 2 de Junio de 1662 . Si pensamos que nuestro biografiado y éste fueran la misma persona, habrían transcurrido seis años (si en 1656 tenía 8 ó 9 años, ahora en 1662 tendría 14 ó 15, una edad perfecta para ejercer como "infante mayor"). Pero ese mismo año, el 28 de Agosto, se cita a otro (o acaso el mismo) "Infante de Brea, escolano", que, como va dicho, realiza estudios de maestro de capilla - era por tanto, asimismo de edad avanzada para ser infante de coro-. Todavía un año más tarde, el 26 de Noviembre de 1663, encontramos la siguiente información capitular: "Recibió el cabildo por infante a Baltasar Sanz de Brea después de haberlo examinado". Éste al menos, con nombre completo, parece que fuera distinto al anterior dado que, como se dice, ingresó en 1663. Pero en ese caso, no coincidiría con los datos aportados por Bonastre, pues parece raro que entrara como infante con unos 13 años... Por último, poco después, el 1 de Diciembre, aún se menciona al "Escolano Mayor el infante de Brea", que sin duda debe ser el mismo de todas las noticias anteriores, a excepción de la de Noviembre de 1663, precisamente, la única que da el nombre completo del niño en cuestión, y que es el mismo de nuestro biografiado. (?).

23. No obstante lo referido en la nota anterior, de todos los diccionarios biográficos de música consultados, incluidos los enciclopédicos, su entrada sólo aparece en el Diccionario de la Música Labor de Joaquín Pena e Higinio AngLÉs (Barcelona, Labor, 1954, vol. II, p.1965), donde lo único que se dice es que se trata de un "compositor español desconocido del siglo XVII". Lo que sí se sabe con certeza es que fue maestro de capilla de la Catedral de Tortosa desde, al menos, alrededor de 1673, hasta su muerte, a principios de enero de 1708 - como así lo constatan las Actas Capitulares del archivo de dicha catedral (10 de enero de 1708 , fol.7v) —, cuando se señala que fue maestro en dicha seo durante, al menos, treinta y cinco años.

24. En la Clavería 141 de 1701 del Arxiu Històric de les Terres de l'Ebre (Tortosa) se recoge el siguiente documento: "gasto Dunsayner / Al Primer de Maig de MDCCI Posa / en data dit clavari de dita provisio Vinty / quatre lliures pagades á Joan Sarago / sa dunsayner per haver tocat deu / Dies en les festes que ha fet la Ciutat / pera la Coronacio del Rey". Este escrito nos aporta el nombre de uno de los músicos que ofreció sus servicios a la ciudad tocando la dulzaina durante los diez días que duraron las fiestas: Joan Zaragoza, de quien cabe pensar que sería también uno de los dulzaineros que participaron en la procesión del primer día. En cuanto a la Clavería que nos ofrece tal información, por el simple hecho de tratarse de un documento que registra los gastos de la ciudad, nos está indicando implícitamente que era ésta misma, y no el cabildo, la encargada del pago de, al menos, este músico, en dichas celebraciones.

25. La Virgen de la Cinta ha sido, desde muy antiguo y hasta la actualidad, muy venerada en la ciudad de Tortosa. La reliquia de la Santa Cinta data del 25 de marzo de 1178, noche en que según la leyenda, la Virgen descendió milagrosamente a la tierra y le entregó su cíngulo a un humilde sacerdote. Durante, al menos, los siglos XVII y XVIII que nos interesan aquí, dicha reliquia se trasladó en numerosas ocasiones a Madrid con motivo de partos reales, dado que, conocedores de la práctica devota de las mujeres tortosinas próximas a ser madres, algunos monarcas - desde 1629 con el Rey Felipe IV, prácticamente hasta la actualidadsolicitaron al Cabildo de Tortosa que dicha reliquia mariana fuera llevada a Madrid con motivo de los diferentes embarazos de las correspondientes reinas o infantas. Actualmente, la fiesta de la Santa Cinta se celebra en Tortosa, todos los años, el primer domingo de septiembre. [Sobre este tema puede verse: -Manuel Beguer Pinyol: La Santa Cinta de Tortosa, breve historia documenta$d a$. Tortosa, Real Archicofradía de Nuestra Señora de la Cinta, 1964, pp.17-30 y pp.41-43; -Joan Amades: Imatges de La Mare de Déu trobades a Catalunya. Barcelona, Selecta-Catalònia, 1989, pp.140-141; -Francisco Martorell: Historia de la Santa Cinta. Tortosa, Biblioteca Ebrenca, 1996; -Joan Moreira: Del folklore tortosí(Segona Part). Costums, ballets, pregaries, tradicions, jocs

Anuario Musical, 59 (2004) 
decir, en definitiva, una procesión que era todo un espectáculo de sonido, olor, luz y color, con música, luminarias, flores, tapices y colgaduras que se tendían de los balcones, etc., la cual terminó bien entrada la noche. Se detuvo en tres ocasiones, en cada una de las cuales se cantó un villancico, de los tres que Baltasar Sanz ${ }^{26}$ había compuesto para el caso y cuyos textos fueron los siguientes:

\section{VILLANCICO I}

\section{ESTRIVILLO}

1. LVZES Sagradas que al Sol Mendigays los luzimientos, Que en las sombras de la noche Admiran ojos atentos.

2. Aves que animadas plumas Habitays de el Ayre el Centro, Y Clarines de la Aurora $\mathrm{Al}$ Sol llamays soñoliento.

3. Pezes que el liquido vidrio Surcays Navios veleros Sin temer de Eolo iras, Ni la escarcha de el Enero.

4. Flores que de los sentidos

Ojeto soys alagueño, $O$ yà dispenseys fragancias, $\mathrm{O}$ yà los colores regios, Luzes, Aves, Pezes, Flores En quien cifradas se vén con acierto Las propiedades.

De tierra, de Agua, de Aire, y de Fuego, Atencion à lo dulce de mis acentos, Que en el dia, que à su Rey FELIPE Sucessor digno de tanto Imperio Aplaude el afecto Es justo, que acudan Al Iubilo tierno, Con Flores la Tierra,

\section{COPLAS}

1 YA el Fuego de nuestro Amor oy todo es luzes, y es bien, que sin saber abrasar, se mire en todos los pechos arder, y à FELIPE el Fuego con Luzes le dé el parabien.

2 Yà el aliento de el cuydado es respiracion cortès; sin que el ahogo se atreva, à servir de laço contra toda ley. Y à FELIPE el Ayre con Aves le dé el parabien.

3 Yà el Cristal de la Lealtad le sirve augusto Dosel; y aunque paresca elevado tarima se ofrece à sus Reales Pies. Y à FELIPE el Auga [Agua] con Pezes, le dé el parabien.

4 Yà en gloriosas esperanças se vé su luz florecer; oxala lleguen los frutos, que aguarda el cuydado, y espera la Fè. Y à FELIPE la Tierra con Flores, le dé el parabien.

i cançons del camp $i$ de la ciutat de Tortosa. Tortosa, Biblioteca Ebrenca, 1999, pp.474-438; -Carles Cid, e Irene AstorT: Les imatges de la Verge i dels Sants a Catalunya. La Mare de Déu de la Cinta. Barcelona, Montaber \& Simon, s.a., pp.29-48].

26. Hasta la fecha, sólo he podido localizar unos pocos villancicos de este "gran poeta y gran músico"—de los que se conserva tanto la música como el texto-, en el archivo de la iglesia de San Pedro de Canet de Mar (lugar que de momento no ha sido relacionado directamente con este músico) y en la Biblioteca de Cataluña, con lo cual, resulta también interesante la aportación de este impreso que describe las festividades tortosinas, por cuanto nos ofrece los textos íntegros de tres de sus villancicos, así como la información implícita de que fue él mismo quien escribió dichos textos y quien, en general, escribía tanto la parte musical como la parte literaria de sus composiciones. 
Con Aves el Viento,

Con Luzes el Fuego,

Para que festivos nuestra dicha aplaudan

Las Flores, las Aves, las Luzes, los Pezes,

En la Tierra, en el Ayre, en el Fuego, en el Agua.

Nótese que el propio texto de este primer villancico es testimonio del concepto barroco de fiesta como espectáculo "integral", en cuanto alude a elementos visuales - luces y fuego-, sonoros - clarines - y olfativos —flores_, además de, por otra parte, utilizar el típico tema de numerosas composiciones hispánicas de esta época, de los cuatro elementos (tierra, agua, aire y fuego).

\section{VILLANCICO II}

\section{ESTRIVILLO}

HOrrorosas injurias de los ojos, Efectos de el dolor de vn bien perdido, Luzid, al centro triste de el Erebro:

Que yà es todo luz, y yà es todo alivio.

Lucid, luzid, luzid,

Que el flamigero Sol de FELIPE,

En los Montes Españoles,

Oy raya feliz, y amanece propicio;

Con tan sagrados anuncios,

Que lo menos, lo mas es que advertimos.

Albricias Españoles;

Que yà ha amanecido

Decediente feliz de el quarto Planeta,

El Planeta Quinto.

Huyan las penas,

Cessen los suspiros,

Pausen los sollozos,

No se oygan gemidos;

Que qando esperanças, yà possessiones,

Publican efectos de tal causa dignos;

Son desayre de animos fieles,

Penas, suspiros, sollozos, gemidos.

$\mathrm{Y}$ assi solo se escuchen

En ecos repetidos,

Albricias españoles, \&

\section{COPLAS}

1 Ya Coronado Monarca felize goza FELIPE el Imperio Español; y con razon; porque à fortuna, y à naturaleza, vnimos el lazo de la obligacion.

2 Yà sus Vassallos con gusto, celebran, de su Monarca la coronacion; y con razon; porque, quando sucession no fuera, devia ser por su esfuerço, eleccion.

3 Yà, en las Aras Sacras del afecto cada vno ofrece su fiel Coraçon; y con razon; que al amor, que de su Rey espera, deve ofrecer cada vno su Amor.

4 Yà, Tortosa, leal como siempre, sus atenciones le rinde veloz; y con racon; porque à sus palmas añada por timbre de essos afectos la orla mejor.

Obsérvese que también aparecen alusiones a la luz, el sonido y los elementos en el texto de este segundo villancico. Resulta asimismo curiosa la referencia a Felipe con el ordinal castellano (V) y no 
el aragonés (IV), al considerarlo el "Planeta Quinto"27. Por otra parte, aunque en el estribillo se le considera "decediente feliz de el quarto Planeta" (Felipe IV) ${ }^{28}$, la copla segunda, sin embargo, alude a que, caso de que su coronación no se hubiera debido a cuestiones sucesorias, ésta hubiera estado plenamente justificada por "su esfuerzo", el cual le devengaría ser elegido ("eleccion") [!?] ${ }^{29}$.

El último de los tres villancicos de Baltasar Sanz cuyo texto recoge este impreso es el único que incluye explícitamente la participación de instrumentos — chirimías - en su interpretación ${ }^{30}$.

\section{VILLANCICO III DE CHIRIMÍAS}

\section{ESTRIVILLO}

1. HA de la quinta Esfera,

En cuyo augusto alcaçar cristalino, Impera Marte Dios de las batallas, Coronado Monarca en sus distritos. Oyd, escuchad, diafanos zafiros.

Que mejor Astro, que el quinto Planeta, Oy raya en España en FELIPE QUINTO. Oyd, escuchad, diafanos zafiros.

2 Ha de esse alegre Hybleo, Que es Palacio, ò Dosel vegetativo, Donde la Paz descansa en ocio blando En lecho de Claveles, y Iacintos Oyd, escuchad, primores floridos;

\section{COPLAS}

VAliente Marte le espera, oy los Españoles brios; que tan heroycos alientos son dignos de tal Caudillo. Viva mil siglos, \& c. Pacifico Rey le goza de sus Vassallos lo fino, $y$ es su esfuerço antecedente de lo que infiere el Cariño. Viva mil siglos, \& c. Valor, y Piedad extremos casi siempre divididos, solo su animo Real

27. Aunque en la p.3 del impreso en cuestión el observador anónimo de estas festividades tortosinas se refiere a dicho monarca como "Don FELIPE V de Castilla, y IV en Aragon", la mayoría de las alusiones al mismo que aparecen en la descripción de las diferentes manifestaciones festivas realizadas - textos poéticos o de villancicos, vítores, etc._-, como se irá viendo, se realizan con el ordinal castellano.

28. En este sentido, nótese que se emparenta aquí a Felipe de Anjou (o Felipe V), con Felipe IV, pues el Duque de Anjou era nieto de Luis XIV de Francia - emparentado directamente a su vez con Felipe IV—; pero no se le emparenta en cambio, con quien hubiera sido lo lógico, como inmediato antecesor en el trono, Carlos II (emparentado, éste sí, con el pretendiente austríaco, Carlos — poco más tarde Carlos III en Cataluña-). La prueba más evidente de estas relaciones "familiares" es la del nombre propio con el que querían reinar ambos pretendientes a la corona española: el francés, "Felipe" (Borbón) —relacionado con dos reinados hispánicos más atrás en el tiempo-, y el autríaco, "Carlos" (Habsburgo) — relacionado directamente con el rey fallecido sin descendencia directa, Carlos II- Todo esto lo corrobora el hecho de que Felipe IV fuera conocido como "el rey planeta", calificativo que se aplica también aquí a Felipe V (por otro lado, nieto de Luis XIV de Francia, "el rey sol").

29. Sorprende esta afirmación... de hecho, se está reconociendo, con este impreso, y con las extraordinarias fiestas en su honor, etc., la legitimidad del nuevo rey Felipe V, aunque, por otro lado, ya se está planteando aquí una temprana sombra de duda al respecto: en cierto modo, viene a decirse algo así como que, "y si aún por sucesión no estuviera legitimado, le elegiríamos por sus cualidades personales...". Contrariamente a lo que sucedería actualmente, dicho planteamiento no parece que fuese muy positivo en la época, sobre todo si se tiene en cuenta que se trataba de un tiempo en el que la máxima autoridad y legitimación del poder se justificaba con razones puramente sucesorias o "de sangre" (aún faltaba mucho para que llegaran los acontecimientos y consecuencias de la Revolución Francesa, y el absolutismo monárquico - siempre tendente a emparentarse con los emperadores de cara a fortalecer su legitimidad: Roma, Carlomagno..._- estaba en su máximo apogeo...). ¿Eşconderían ya estas palabras un cierto posicionamiento temprano de Tortosa, a propósito de lo que posteriormente sucedería en la Guerra de Sucesión cuyas primeras revueltas empezarían en tierras de Tarragona apenas unos meses más tarde? ... [Vid. documentación sobre las revueltas y guerra en general en la nota 5].

30. A lo largo del presente estudio se ha ido manifestando el gran protagonismo de este instrumento "alto" en las fiestas descritas, tanto en actos religiosos como civiles. 
Que essa Deydad que veneran los Orbes

Se adora oy por el QVINTO FELIPE,

Oyd, escuchad, primores floridos;

3 Extremos contradictorios,

No supo el Ingenio vnirlos jamàs:

Marte, y Paz lo son : luego no pueden

Vnirse extremos de Marte, y de Paz,

Oyd, escuchad Eco oyd, escuchad:

1 Yo Marte le venero,

2 Yo Iris de Paz le admito.

1 Oyd, escuchad diafanos zafiros,

2 Oyd, escuchad primores floridos,

3 Oyd, escuchad,

Los dos Oyd, escuchad,

4 Ha de el Cielo, y la Tierra,

Que entre fatales, justos paracismos,

Entre la Paz, y Marte os encontravays

Con los horrores graves de indecisos.

1 Oyd, escuchad diafanos zafiros,

2 Oyd, escuchad primores floridos.

1 Que mejor Astro, \& c.

2 Que essa Deydad, \& c.

3 Oyd, escuchad,

Que no es facil hallar solucion,

Para la vnion de Marte, y de Paz,

4 Oyd, escuchad prevenidos,

De que en feliz Maridage,

Oy se enquentran comprehendidos

De Marte los alientos,

De la Paz los olivios;

Quando feliz se Corona en España

Nuestro Monarca FELIPE QVINTO,

Viva, mil siglos,

Viva, viva FELIPE QVINTO. puede facilmente vnirlos.

Viva mil siglos, \& c.

Y pues Marte, y la Paz son

Polos de vn Reyno temido,

con razon España espera

ser assombro de los siglos.

Viva, \& c.

Las actas capitulares del archivo de la catedral de Tortosa también recogen información respecto a las celebraciones de esos primeros días, así como respecto a las composiciones escritas por el maestro de capilla para las mismas, que en dicho momento, era Baltasar Sanz:

"Festes per la / Coronacio / del Rey

[...] Deliberarunt que les festes en accio de gracies / a Deu per la Convenguda a Madrit / y coronacio del Rey (que Deu g.de) Lo / Duch de Anjou net Segon del I[lustr]e Lluis catorse / Rey de frança se fassen lo dia vint y tres / dia de Sant Jordi y lo dia 24. La primera este / Capitol fentse en la tarde una Solemnísima / processo ab asistencia de les Religions en la / qual se porte la Sagrada reliquia de la S.ta 
/ Cinta de Maria SS.ma Señora nostra y la / segona festa esta ciutat solemnisant dites dos festes / ab tres dies de Luminaries ab tochs Solemnes / de campanes comensant lo dia $\underline{22}$ a mitg dia / y en la nit a toch de oracio continuantse los / altres subseguents dies en esta conformitat / y per dit efecte se escriga al P. M.e fr. Fran.co / Castell del conv.t de nostra Señora de Benifassa / per lo sermo en la festa fara este Capitol lo dia / 23. Y axi matex se previnga tea pera dites / Luminaries en la forma acostumada, dexantho / tot a la bona direccio dels Señors Comissaris no / menats per este efecte pera que disposen lo que / convinga obrarse" ${ }^{31}$.

"Presencia / M.e de capella

[...] Deliberarunt se done com donaren al M.e / de Capella la presencia demana en estos / dies que ha menester pera prevenirse en los / Villancicos pera estes festes del Rey (que / Deu g.de)"32.

Ese mismo día, finalmente, por la noche, el gremio de labradores representó una función al magistrado, para la cual, las calles se adornaron con ricas tapicerías y flores: un desfile, que dio la vuelta a la ciudad, de sesenta y cinco parejas a caballo - todos con hachas blancas que "al moverse parecian errantes Cometas"- y un carro triunfal muy adornado con flores y hojas "al compàs de sonoros Clarines" con un trono que llevaba la imagen del Santo Labrador —alrededor del cual ardían 16 hachas-, así como "un lugar acomodado para la Musica", en el que distintos instrumentos repetían "uniformes, y gustosas consonancias; $\mathrm{Y}$ en los lugares mas publicos se cantavan algunos tonos con letras hechas al intento". También durante ese primer día se pudieron leer, por diferentes lugares de la ciudad, algunas letras y/o versos (Décimas, Epigramas, etc), de los que el autor del impreso estudiado sólo recoge unos cuantos por considerar que éstos "fueron muchos, assi Latinos, como Castellanos" [y catalanes]. ${ }^{33}$

31. E: TO, Actas Capitulares, 8 de abril de 1701, fols. 102-102v. [Traduzco a continuación el documento expresado:] "Fiestas por la Coronación del Rey. [...] Se delibera que las fiestas en acción de gracias a Dios por la llegada a Madrid y coronación del Rey (que Dios guarde), el duque de Anjou, nieto segundo del Ilustre Luis XIV rey de Francia, se hagan el día 23, día de Sant Jordi y el 24. La primera [fiesta], este Cabildo hará por la tarde una solemnísima procesión con asistencia de las Religiones, en la que se llevará la Sagrada reliquia de la Santa Cinta de María Santísima Señora Nuestra [sobre la "Santa Cinta" véase nota 25], y la segunda fiesta, solemnizando esta ciudad dichas dos fiestas con tres días de luminarias con toques solemnes de campanas, empezando el día 22 al mediodía y por la noche a toque de oración, continuándose los otros subsiguientes días en esta conformidad, y para dicho efecto se escriba al padre maestro fray Francisco Castell del convento de Nuestra Señora de Benifassà para el sermón que en la fiesta hará este Cabildo el día 23. Y asimismo se prevenga tea para dichas luminarias en la forma acostumbrada, dejándolo todo a la buena dirección de los Señores Comisarios nombrados para este efecto para que dispongan lo que convenga obrarse".

32. E: TO, Actas Capitulares, 15 de abril de 1701, fol. 109. [Traduzco:] "Presencia, Maestro de capilla. [...] Se delibera que se dé, como se dio al maestro de capilla, la presencia que pide en estos días y que ha menester para prevenirse en los Villancicos para estas fiestas del Rey (que Dios guarde)".

33. Véase, por ejemplo, una de las dos décimas escritas sobre lo más alto de la puerta de la plaza del Estudio de Gramática: "En tu gran Coronacion,

FELIPE, qualquier Ciudad

Se propone su lealtad

Con gloriosa emulacion.

Mas yo sin afectacion,

Solo te quiero acordar,

Que me sabrè señalar,

En timbre tan merecido,

Pues Fidelissima he sido,

Y siempre serè Exemplar". 
El segundo día de la celebración —-domingo 24 abril — fue el elegido como suyo por la ciudad y, aunque por la mañana también se cantó una misa en la catedral (que seguía adornada como el día anterior y había en el altar "luzes quantas pudieron caber en su dilatado ambito") en la que "los Musicos cantaron como unos Angeles" y luego hubo sermón y se celebró el Oficio, el citado documento no hace referencia alguna a la interpretación de composiciones concretas. Por la tarde, por su parte, el gremio de los Labradores organizó un desfile - formado por diferentes tropas, en el que unos iban vestidos de segadores, otros de mujeres, etc.- y, luego, en la Parroquia de Santiago, un baile al que acudieron más de 150 parejas - las mujeres vestidas muy engalanadas - en el cual, evidentemente, y aunque no nos da constancia explícita de ello el impreso estudiado, habría sin duda participación musical.

El lunes 25 de abril otros gremios de la ciudad se unieron para representar la segunda función, que finalmente consistió en un concurso: se formó un fingido bosque en la plaza mayor y, entre otras cosas, se soltaron distintos animales que había que atrapar. Antes de dar comienzo la misma, "El Magistrado se puso en el lugar se le tenia prevenido, y à las dos y media de la tarde se oyeron las Marciales vozes de Clarines, y Caxas, que motivaron alegre bullicio" y los maestros de las cuatro cofradías $^{34}$ hicieron su entrada, seguidos de soldados a pie y a caballo, cazadores seguidos de una trompeta que tocaba a marcha, la guardia de la cuchilla al compás de las cajas, etc.

Del martes 26, elegido por el magistrado para su corrida de toros, sólo tenemos constancia de que hubiese presencia musical cuando, a las dos, los procuradores se dirigieron hacia la plaza, seguidos de "diferentes instrumentos músicos, que hacían alegre la pompa de la entrada" 35 y parece ser que, a causa de la lluvia, la corrida se suspendió a partir del tercer toro, así como el baile previsto para la noche.

El miércoles 27, la fiesta de la tarde se había encargado a los gremios de "Santa Barbara de Perayles [pelaires], y de la Santissima Trinidad de Texedores", los cuales, para celebrar la ocasión también con una representación, montaron un gran salón con un elevado trono - y detrás del mismo un lugar destinado a la música-, muy adornado con telas, etc. Hacia las dos, después de llenarse todo el circo, empezó el espectáculo con "el militar ruido de Clarines, y Caxas, y entrò en la Plaça una luzida comitiva de quarenta lanças à cavallo con muchas galas, y plumas, luego al compàs de las Caxas marchava un Capitàn, que fingia ser lo de la Guardia [...]”. Tras ellos entró el Rey (de la representa-

Fue precisamente Felipe IV quien, en 1641, concedió a la ciudad de Tortosa el título de "Fidelísima y Ejemplar" para recompensar su obediencia y lealtad. [Véase: -Daniel Fernández y Domingo: Anales o Historia de Tortosa. Tortosa, Biblioteca Ebrenca, 1997, p.143].

34. Se trata de los gremios "de Corpus Christi, los Calsateros de San Martín Sastres, los Zapateros de Santa Cruz y los Toqueros de Nuestra Señora de los Angeles".

35. Aún así, cabe destacar la existencia de diferentes documentos que atestiguan la participación de los músicos en las lidias de toros en territorios hispánicos. Así, el Manual de Novells Ardits o Dietari de l'antic Consell de la ciutat [de Barcelona, vol. VII, p.369, 3-XII-1601] da noticia de una corrida de toros amenizada por la música de ministriles y muchas trompetas [Citado en: -Francesc de Paula Baldelló: La música de l'antic consell barceloní, notes històriques. Barcelona, Imprenta Barmar, 1929, p.61]. También Viana CADENAS GaRCía nos ofrece información ("La vida musical en la Caracas del siglo XVII", en Campos interdisciplinares de la Musicología. Madrid, Sociedad Española de Musicología, 2001, vol.I, pp.57-59), respecto a que en la segunda mitad del siglo XVII, los músicos que formaban parte de la capilla de la catedral de Caracas colaboraban normalmente, con sus voces e instrumentos, en los festejos públicos de la ciudad en sus variadas manifestaciones festivas con presencia musical, entre las que se encuentran las lidias de toros. 
ción, un joven de unos 18 años) en un coche vestido "a la española"36 y, después de que las diferentes comitivas ocuparan sus respectivos puestos, "Cantó la Musica un tono hecho para el caso, y luego se dexò ver en la Plaça al son de un Clarin festivo una numerosa comitiva à cavallo", tras lo cual, un representante de los gremios que hacía de embajador hizo las pertinentes reverencias al trono y, seguidamente, se volvió a cantar otro tono. De nuevo, por la noche hubo en la plaza un lucido baile que en este caso fue también concurso, al que acudieron, en esta ocasión, más de 80 parejas y en el cual tampoco pudo faltar, evidentemente $-\mathrm{y}$ aunque no tengamos constancia explícita de ello-, la presencia musical.

El día 28 por la tarde, otros gremios se habían propuesto ofrecer una corrida de toros que también la lluvia impidió en esa ocasión. Aún así, más motivados en las celebraciones por la llegada a la ciudad — hacia las tres de la tarde — del Conde de Hien (hijo primogénito del Duque de Nohallas) ${ }^{37}$, el gremio de los marineros interrumpió su labor cuando, al pasar dicho Conde por el "Coll de Balaguer" ${ }^{38}$ del Ebro para verles pescar, le ofrecieron un sencillo espectáculo en una fragata vestidos de moros, con muchos disparos y al son de las cajas, como anticipo de la fiesta que tenían preparada para ofrecer a la ciudad el día 1 de mayo.

Del día 29, destinado a los toros que no se pudieron lidiar el día anterior ("se corrieron 16 fieras muy bravas, con gran destreza de los toreadores"), no se nos describe presencia musical algu$\mathrm{na}^{39}$.

El sábado 30, la Cofradía de San Telmo levantó en mitad de la plaza, para realizar su representación, un elevado castillo - adornado con estandartes rojos bordados con medias lunas, etc. para simular una fortaleza a la cual se tenían que retirar los moros perseguidos por los cristianos-, y hacia las tres de la tarde, "al repetido son de Clarines, Caxas, y muchos tiros, à que correspondiò con no poco fuego el Castillo, entrò en la Plaça un Turco con alfange ceñido [...]. Guiava una tropa de hasta veinte muchachos vestidos à la Turquesça, que ninguno passava de diez años, muy luzidos, à quienes

36. Posible alusión indirecta a que el nuevo monarca extranjero - de origen francés-, asume desde el primer momento las costumbres y tradiciones del pueblo que ahora rige, acaso con vistas a buscar su complicidad y simpatía...

37. En este caso, la mención al Duque de Nohallas (o "Noailles") se refiere a Anne Jules de Noailles (*1650; †1708), padre del aquí citado como Conde de Hien (o "Ayen"). No hay que confundir a este Duque de Nohallas — padre-, con quien realmente desempeñó un papel de cierta relevancia en la Guerra de Sucesión española, su hijo - citado en nuestro texto como "Conde de Hien”, pero conocido en el ámbito hispánico, unos años más tarde, con el mismo título que aquí se refiere a su padre, esto es, el "Duque de Noailles"-, llamado Adrien Maurice de Noailles $(* 1678 ; \nmid 1766)$. Este último, general de Luis XIV, fue enviado en diversas ocasiones por el rey sol para restablecer el poder de Felipe $\mathrm{V}$ en Cataluña, precediendo las tropas francesas. Un ejemplo de las actuaciones militares en territorio catalán de su poderoso ejército, lo constituye la caída de Gerona en manos borbónicas en 1711. Este general francés reunió en su persona diversos títulos nobiliarios y cargos de importancia en Francia, como "Duque de Noailles" (a la muerte de su padre), Par de Francia, Marqués de Montclar, Conde de La Motte-Tilly y de Nogent-le-Roy, Vizconde de Carlux, Decano de los Mariscales de Francia y Caballero del Toisón de Oro. Seguramente, en nuestro documento objeto de estudio, se le cita todavía como "Conde de Hien" (sic. Ayen), debido a que sería todavía su padre quien ostentaría el título de Duque de Nohallas (sic. Noailles) hasta su muerte en 1708. No obstante, como se conoce a nuestro protagonista por lo general en los libros de historia españoles y catalanes, es por su título posterior, heredado de su padre, de "Duque de Noailles", lo que podría dar lugar a posibles confusiones. [Pueden verse algunas referencias en: -Joan MERCADER I Riba: Felip V $i$ Catalunya. Barcelona, edicions 62, 1985, pp.125, 282-283, 399-400, 424; -Josep Maria ToRras I Ribé: La guerra de successió $i$ els setges a Barcelona (16971714). Barcelona, Rafael Dalmau, 1999, pp.168, 200, 205-206, 277-282, 336].

38. Por "Coll de Balaguer" se entiende todo el territorio de la provincia de Tarragona que, actualmente, va desde Hospitalet de l'Infant hasta el Perelló. Durante siglos fue un lugar de paso muy transitado, tal y como explica Eufemià FORT I CoGul en El trànsit pel Coll de Balaguer. Barcelona, Rafael Dalmau, 1974.

39. Lo cual, obviamente, no significa necesariamente que no la hubiese... Véase nota 35. 
hazia $\operatorname{son}^{40}$ otro Turco con una vihuela cerrando la tropa ${ }^{41}$. Dieron buelta al circo dançando una alegre zambra, con diversidad de lazos, y movimientos, que diò notable gusto". Tras repetir de nuevo los marciales sones de los clarines, las cajas y los tiros, correspondidos en el castillo, entró en la plaza una simulada fragata que parecía verídica (con sus ocho remos por banda, las velas, un cañón en la proa, tres pedreros por banda, etc., y algunos textos como por ejemplo una redondilla escrita en la proa $^{42}$, otra en el estandarte - bordado con medias lunas- situado en la popa ${ }^{43}$, etc.), la cual, tras realizar los pertinentes saludos con tiros y cañones, repartió copias de un texto desafiando a los cristianos, entre los Ilustres Procuradores ${ }^{44}$. De nuevo sonaron los clarines y las cajas, mientras se retiraba la fragata turca para que hiciese su entrada la cristiana (similar a la turca, pero con diferentes banderas y textos $)^{45}$, también realizando algunos tiros que fueron correspondidos por los moros. Del mismo

40. De la redacción, parece colegirse que los citados veinte muchachos, muy probablemente cantaran, pues la vihuela, "les hacía son", es decir, les acompañaba...

41. Los clarines y las cajas eran instrumentos que, cumpliendo con una de las funciones para las que más habitualmente se destinaban, y también en el caso de Tortosa, acompañaban todas las entradas y los desfiles, pero nótese que, en este caso, aparece por primera vez y justamente en un contexto asociado a lo moruno, la vihuela. En cuanto a la presencia musical de clarines y cajas (trompetas y timbales o tambores) en los desfiles o fuera de ellos, podemos constatar múltiples ejemplos documentados en la época. Por señalar algunos, referidos tanto a Cataluña, como a la corte en Madrid e incluso a Latinoamérica, podemos aproximarnos a los siguientes: sobre la participación de los músicos del Consejo de la Ciudad de Barcelona en ocasiones festivas extraordinarias, Francesc de Paula Baldelló (La música de l'antic consell barceloní..., op. cit., pp.57-61) nos describe la entrada en la ciudad del Duque de Osuna en 1667, cuando sonaron timbales, trompetas y ministriles. También Paúl R. LaIRD ("Los villancicos del siglo XVII en el Monasterio del Escorial", en La Música en el Monasterio del Escorial. Actas del Simposium. Madrid, Instituto Escurialense de Investigaciones Históricas y Artísticas, 1992, pp.169-225) testimonia el uso de clarines y cajas en las festividades realizadas con motivo del Centenario de El Escorial celebradas del 29 de agosto al 6 de septiembre de 1663. Y según Viana CadENAs García ("La vida musical en la Caracas del siglo XVII"...,op. cit.,pp.57-59), en la segunda mitad del siglo XVII, la celebración del patrón de la ciudad de Caracas - Santiago Apóstol - tenía como señal de inicio de fiesta el sonar de los clarines. Entre un largo etcétera.

42. La redondilla de la proa era la siguiente:

"Oy con violencia importuna

Todo lo hemos de rendir,

Que al averle de esgrimir,

43. La redondilla del estandarte era:

Cada alfange es media Luna".

"Oy el triunfo ha de ser nuestro,

Publicandole la Fama;

Quedando llena la Luna

44. El texto empezaba como sigue:

De el fin de nuestra esperança".

"Ilustre, Noble, antigua fiel Iberia

à tus pies una Fusta peregrina,

que el mar fiò altaneras esperanças

endereza la proa siempre altiva". [Etc.]

Sobre las diferentes opciones de difusión de textos utilizadas normalmente en este tipo de celebraciones festivas - tarjetones con versos, hojas volantes arrojadas desde un carro, textos en escudos, etc.-, véase: -José María DíEz BorQuE: "De los siglos de oro al siglo de las luces”, en Historia de los espactáculos en España (Andrés Amorós y José María DíEz, coordinadores). Madrid, Castalia, 1999, pp. 207-238. Y sobre los géneros y formas de la poesía visual en la fiesta y la celebración, así como los modos y procedimientos de su difusión, véase: -José María Díez Borque: "Poesía en la calle, de los siglos de oro al siglo de las luces" (Ibid., pp.419-454). [Sobre la naturaleza del texto aquí incluido, adviértase la identificación de Tortosa con su río, el Ebro (del latín "Iberus" - "Ebrus"...), - y éste, en la zona más ancha de su cauce_, y de ahí, con un sentimiento hispánico por antonomasia: la antigua Tarraco como capital de la Hispania en tiempos de la vieja Roma, o la raigambre "ibérica" de Tortosa a partir del importante río que incluso identifica su nombre - Iberus - con el de toda la península - Iberia-].

45. La fragata cristiana tenía escrita una cuartilla en la proa que decía:

"Si à Dios nuestra Fè venera,

Y èl nuestro valor anima,

Quien nos haga resistencia,

Yà se anuncia su ruina." 
modo que la anterior, esta embarcación dio la vuelta a la plaza al son de clarines, cajas y tiros, y un embajador desembarcó, junto con algunos soldados, y dio al procurador primero unos versos ${ }^{46}$. Finalizadas las presentaciones de las construcciones hechas para el caso ${ }^{47}$ y de los actores, empezó el fingido combate entre moros y cristianos ${ }^{48}$, también "al belicoso son de Caxas, y Clarines, disparando repetidas vezes los Cañones, y pedreros, y arrojando muchos fuegos artificiales" y, concluida la representación sobre las 9 de la noche, se prendió fuego al castillo —el cual finalmente quedó reducido a cenizas - al tiempo que se disparaban muchos cohetes.

El numeroso Gremio de los Pescadores fue el encargado de realizar los festejos del domigo 1 de Mayo. Para su representación — también una batalla de "moros y cristianos" no podía ser menos, el río como escenario.

Y en la popa, en alto, llevaba un estandarte real de color rojo, con una cruz de oro y las Reales Armas de Aragón bajo las cuales se podía leer esta cuartilla:

"Pues oy à FELIPE QUINTO,

España venera Rey,

En su nombre pelear,

Yà es lo mismo que vencer."

[Una vez más llama la atención que la mayoría de los versos de la descrita festividad tortosina se refiriesen a Felipe V, prefiriendo de este modo la numeración castellana, en vez de la aragonesa de Felipe IV].

También se elevaba, en la popa, una almohada con una corona real y dos leones, y en la proa, otra bandera con las armas de la ciudad de Tortosa y con otro texto de similares características a los anteriores.

46.

"Sacra Tubala, Generosa Iberia,

Tortosa siempre Ilustre; cuyos hijos

de Minerva, y de Marte en los reenquentros

de Laureles se ciñen repetidos". [Etc.]

47. Es decir, se trata de decorados efímeros seguramente hechos de cartón y madera. La articulación de arquitecturas fijas adornadas y efímeras en las representaciones era común en este tipo de festividades. [Vid.: José María Díez BorQuE: "De los siglos de oro al siglo de las luces", op. cit., pp.207-238]. Para nuestro caso concreto, considérese que la fabricación de catafalcos, barcos, castillos, etc., seguramente de dimensiones muy considerables (v.g., el barco tenía capacidad para desplazar cañones y diversas personas - pedreros-), debía comportar una organización bastante compleja entre los gremios de artesanos y particulares, no sólo en lo referido a la construcción de tramoyas y artefactos técnicos (entarimados, simulación marina, etc.) sino, sobre todo, en la coordinación de los diferentes intervinientes: un barco que entra en la plaza en el momento adecuado al tiempo que otro sale, unos músicos que tocan en el preciso instante que requiere la "puesta en escena", unos personajes que actúan, personas que entregan los pliegos sueltos con los versos al efecto, etc. Es decir, todo un mundo, que nos retrotrae a las representaciones escénicas en teatros y coliseos (aunque quizá más cercano en nuestro caso a determinadas escenificaciones en corrales y casas de comedias y hospitales, de arquitecturas asimismo efímeras), pero aquí, hecho todo "al aire libre" y, en cierto modo - aunque ya vemos que no tanto-, "improvisadas".

48. Las representaciones de combates entre moros y cristianos no son, ni mucho menos, una particularidad de estas celebraciones tortosinas. José María DíEz BorQue (Ibid.), al referirse a las numerosas fiestas que se celebraron a lo largo de los siglos XVI, XVII y XVIII, en diferentes ciudades, por multitud de causas vinculadas a la realeza - nacimientos y muertes reales, recibimiento y entrada en ciudades, coronaciones, etc.- nos describe unas celebraciones realizadas en Toledo en 1533 en las que hubo una representación de una batalla entre moros y cristianos también realizada en torno a un castillo (que hicieron para la ocasión carpinteros y albañiles) al que finalmente se pegó fuego, del mismo modo que se hizo con el tortosino. Según Díez Borque, la larga lucha con los musulmanes en los territorios hispánicos y el triunfo final del cristianismo explica la importancia de la fiesta de moros y cristianos no sólo en el Levante — donde sigue viva - sino también en Andalucía, Castilla y Aragón en los siglos XVI y XVII, como articulación de lo religioso y lo profano. Entre los rasgos comunes que se atribuyen a esta fiesta, en las celebraciones tortosinas encontramos los siguientes: desfile de los bandos moro y cristiano, pieza de teatro muy elemental en dos partes con ataques y rechazos verbales de ambos grupos y simulacros de batallas con escaramuzas, danzas y tiros. Por otro lado, la quema final de las construcciones efímeras que se realizaban en la época con motivo de este tipo de representaciones teatrales, recuerda sin duda al actual procedimiento que se sigue, como fin de fiesta, celebrando en Valencia: la "cremà" de las Fallas. [Sobre las fiestas de moros y cristianos véase también: -S. CARRASCO: El moro retador y el moro amigo (Estudio sobre fiestas y comedias de moros y cristianos). Granada, Universidad, 1996].

49. En este caso se trata de la simulación - ahora ya no en tierra como en el caso anterior, sino en el mismo río Ebrode una batalla naval entre moros y cristianos con presencia musical de ministriles y artillería, muy similar a otra de las representaciones realizada en el río Tajo en las festividades de Toledo de 1533. (Véase la nota anterior). En cuanto a las batallas navales en 


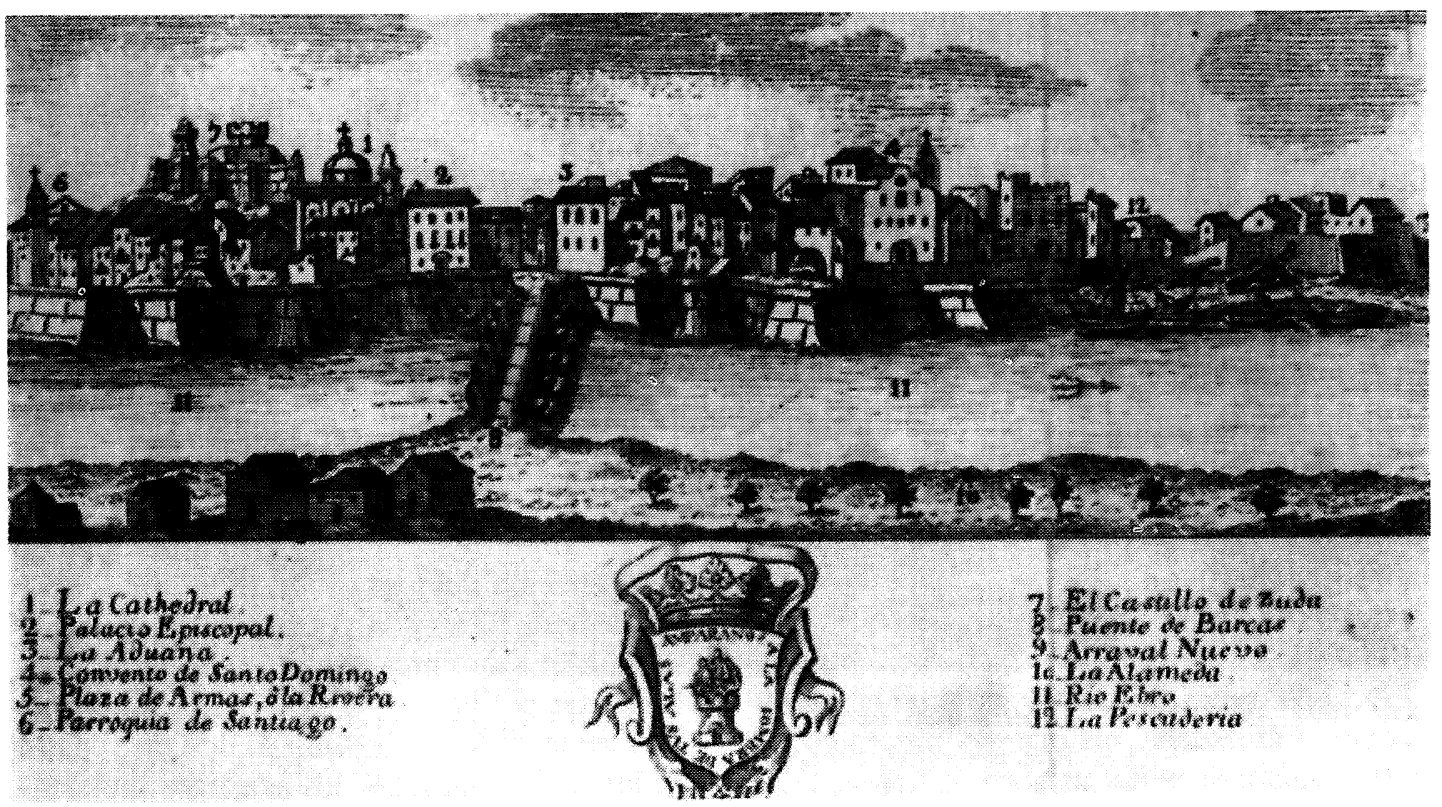

Fig. 7.

El río Ebro a su paso por Tortosa (s. XVII) ${ }^{50}$

Algunos de sus miembros se embarcaron en una galeota muy engalanada y con banderas de varios colores llenas de medias lunas, y otros en dos fragatas pintadas de varios colores y con banderas rojas con las Armas Reales de Aragón en la popa y las de la Ciudad de Tortosa en la proa. Todas las embarcaciones llevaban pedreros, cañones, etc., así como cajas, clarines, chirimías y ministriles ${ }^{51}$. El espectáculo consistió en una larga y simulada lucha — con disparos de cañones, pedreros, arcabuces y escopetas - que finalizó, en esta ocasión, en tragedia: se prendió fuego la proa de la Galeota mora que llevaba algo de pólvora, y este hecho que causó, evidentemente, el horror entre sus tripulantes, tuvo como consecuencia 21 heridos y 4 muertos. Aún así, el mismo gremio suplicó a los pro-

general, según Gino Stefani (Musica Barocca. Poetica e ideologia. Milán, Bompiani, 1987, pp.7-72), su representación era, entre otras muchas que también se plasman en este impreso (carros, estatuas, luminarias, procesiones, representaciones, disparos, campanas, bailes, mascaradas, etc.), una de las características de la fiesta barroca como "teatro total" no sólo en los territorios hispánicos e hispanoamericanos sino también en Italia.

50. Antonio Ripollés Amela: Tortosa Monumental. Tortosa, A. Ripollés Amela, 1999, p.205.

51. La clavería 141 de 1701 del Arxiu Històric de les Terres de l'Ebre (Tortosa) recoge, entre los pagos a ministriles, la siguiente acta: "A V de Maig de MDCCI Posa / en data de dit clavari de dita / provisio sis lliures moneda de / p[la]ta pagades a Jaume Boix / baixoniste per haver tocat les / cherimies en les festes que la p[rese]nt / ciutat ha fet". Si Jaume Boix fue uno de los ministriles [bajonista] que participó en dichas manifestaciones festivas [como antes vimos a Joan Zaragoza, dulzainero], lo más probable es que entre los demás se encontrasen - bien alguno o bien varios-los ministriles Geroni Boix, Roich Feiner y Fran[ces]ch Gassó (sacabuche), ya que todos ellos figuran en las claverías de la ciudad de finales de 1700 (20 de diciembre), en el apartado de salarios, como músicos con la obligación de tocar en todas las fiestas en que la ciudad los llamase. [Se ha visto también anteriormente la participación de una vihuela, aunque se desconoce la identidad de su tañedor]. 
curadores que se continuase con la fiesta prevista, pero la ciudad no lo consintió y ese día todos los tortosinos se fueron a sus casas ${ }^{52}$.

Sin embargo, el lunes día 2 no se celebró fiesta alguna, aunque no por ser el día posterior al de la explicada tragedia sino, simplemente, porque el magistrado se hallaba ocupado, de manera que otros gremios ${ }^{53}$ siguieron como encargados de las celebraciones del día siguiente, 3 de mayo. En dicha ocasión, la fiesta se celebró con un desfile seguido de una representación teatral: el desfile estaba formado por muchos hombres a caballo, muy engalanados - Moros ricamente vestidos, la Guardia, maestros ancianos vestidos "à la Española" con ricas galas, etc.- - y un vistoso y muy decorado carro de 26 palmos de largo y 8 de ancho — que llevaban en hombros 36 hombres cubiertos de tela pintada - con una estatua de la Fama que tenía un clarín en el labio que sostenía con la mano derecha, y un escudo de las armas de Aragón en la mano izquierda, con el texto:

"OY la Fama siempre heroyca,

Dize viva en Aragon,

Don FELIPE de Borbòn."

Una vez llegaron a la plaza, el carro se convirtió en un tablado destinado a la representación y tras las primeras tramoyas, "la Musica se llamò al silencio cantando à quatro esta letra":

\author{
"SOberano Monarca, \\ à quien venera Dueño, \\ à quien espera Padre \\ el augusto Español Noble Emisferio. \\ Enorabuena sea, \\ que de su Trono Regio \\ la elevacion ocupen \\ tus meritos Sagrados, y Supremos. \\ Sirviendo de Corona \\ à sus armas, y alientos, \\ la voluntad con que \\ haze en tu exaltacion estos festejos. \\ [...] \\ Oy la leal Tortosa, \\ con su amor cumpliendo, \\ su Torre à tus pies pone, \\ para elevar sus palmas hasta el Cielo."
}

52. Véase con esto, que el sentimiento de la vida y de la muerte, en la época, era muy distinto del nuestro: aun a pesar de la susodicha tragedia, que fue vista y sufrida directamente por los familiares de las víctimas desde las orillas del Ebro, las fiestas continuaron con toda normalidad durante los días previstos y ya no aparece, en el discurrir festivo de los mismos, referencia alguna a dicho trágico suceso (!). peñeros.

53. Estos eran los gremios de San José, de carpinteros, cuberos, albañiles y canteros, y los de Santa Ana, de torneros y 
Seis fueron los protagonistas de un espectáculo teatral, en el que la música jugó un papel fundamental -interpretación de canciones tanto monódicas como a cuatro voces, interludios instrumentales y danzas — ${ }^{54}$, cinco Ninfas y el Rey. La primera en salir fue la ninfa Ciudad de Tortosa y, tras su representación, "Oyeronse los instrumentos, prosiguiò Tortosa representando, y dentro à quatro vozes lo repitian":

Con Musica ${ }^{55}$ :

\author{
"Oyd, escuchad, advertid, atended, \\ que à las quatro partes de el mundo \\ oy Tortosa convoca fiel, \\ para que assistan al Sacro festejo, \\ que oy le dedica à FELIPE su Rey."
}

A continuación salieron otras cuatro ninfas también ricamente adornadas, por las cuatro partes que había en el carro, representando a "las quatro partes de el mundo", Europa, Africa, Asia y América $^{56}$, y juntas repitieron a cuatro voces la música anterior ("Oyd, escuchad, etc."). Varias veces se interpretó esta pieza a lo largo de la representación, aunque también, todas las ninfas excepto Torto$s a$, cantaron piezas monódicas ${ }^{57}$. En el momento de descubrirse el trono real, sonaron chirimías, y tras seguir con la representación, "dançò la Ninfa que representava à Europa muy à gusto de todos, haziendo diferentes mudanças; al dulce compàs de varios instrumentos, executandolo todo con singular despejo, donayre, y arte" y tras seguir Tortosa con la representación, "puestas en dos alas las quatro Ninfas [...] hizieron un vistoso bayle con diferentes lazos, atentas à los metricos compazes de los instrumentos, cantando cada una lo que le señalavan los versos, repitiendo las demàs, y lo representava, quando cantavan las quatro, Tortosa" "58. Y así siguió el espectáculo: cantó Europa y "Hizose una mudança repitiendo à quatro el tono, y representando Tortosa"; cantó Africa y "Executandose otros lazos [pasos de baile] entre las quatro se repitiò la copla de la misma forma, que en la primera"; cantó Asia y "Lograronse nuevas mudanças arto intrincadas, que se lucieron con felicidad, continuandose

54. La descripción de la presente representación aporta una gran cantidad de datos respecto a la presencia musical en el teatro y, por lo tanto, resulta interesante como ejemplo de la presencia musical en el teatro barroco hispánico. [Sobre este tema, véase: -Louise K. Stein: Songs of Mortals, Dialogues of the Gods. Oxford, Clarendon Press, 1993].

55. Cabe pensar, dado que ya se indica previamente que la interpretación de esta canción se hacía a cuatro voces, que la indicación "Con Musica" se refiera a un acompañamiento instrumental... (?).

56. Otro ejemplo de la presencia de esta temática de las cuatro partes o continentes del mundo, utilizada con frecuencia a lo largo de todo el siglo XVII y buena parte del XVIII (en composiciones musicales en castellano, en poesía, teatro, en artes plásticas - recordemos la célebre y alegórica "fontana dei quattro fiumi" de Bernini en la Piazza Navonna de Roma del año 1651-, etc.), lo encontramos en un territorio hispánico particularmente alejado, empleado como motivo decorativo en las fiestas reales en honor a Luis Fernando I (1725) que tuvieron lugar en Potosí (Bolivia). El testigo presencial de las mismas, Barlotomé Arzáms de Orsúa y Vela, en una de sus descripciones de los adornos del carro triunfal que se exhibió en aquella ocasión, dice que "en los cuatro cantos de los arcos del carro se veían de hermosos bultos las cuatro partes del mundo, Asia, Africa, Europa y América”. [-Carlos Seonne y Andrés Eichmann: Lírica Colonial Boliviana. Bolivia, Quipus, 1993, p.45].

57. El documento no nos aporta dato alguno respecto a si dichas canciones tuvieron o no acompañamiento instrumental.

58. Aparte de la referencia al baile (alusiones a la colocación de las danzantes - "en dos alas"-, y a la descripción más frecuente y subjetiva de la manera de ejecutar el baile - "con singular despejo, donayre, y arte”-), es interesante, aunque vaga, la cita coreográfica a propósito de algunos lances o pasos del baile - mudanzas, lazos-), así como el hecho de que, en este pasaje, encontramos por primera vez una alusión directa a la ejecución musical de instrumentos y voces simultáneamente. 
musica, y representacion"; cantó América y "Prosiguiòse el bayle con nuevos lazos, y en la misma forma, que en las antecedentes coplas [...]" y tras ellas, prosiguió Tortosa la representación y "Con nuevos lazos, y mudanças se prosiguiò el bayle cantando à quatro, y representando la misma copla Tortosa",59, etc. Finalizada la función, volvieron a sonar el clarín y los timbales ${ }^{60}$, al tiempo que todos los implicados en el desfile inicial salían de la plaza tal y como habían entrado, para representar la misma función "en quantos parajes publicos de la Ciudad diò lugar el terreno, siendo siempre numeroso el concurso de los oyentes que llevado de el gusto, y de la admiracion procuravan repetir los de escuchar, y ver".

Ese gran espectáculo teatral ${ }^{61}$ concluyó el último día de las celebraciones de 1701 realizadas en Tortosa en honor a Felipe V, en las cuales, además de todos los festejos descritos, se realizaron también mascaradas ${ }^{62}$ todos los días, y todas las noches "huvo diversion gustosa en la Plaça de diferentes danças mientras no la tuvieron ocupada los [bailes] que hizieron los gremios".

Finalizado el estudio de la presencia musical en las descritas fiestas tortosinas tomando como fuente el impreso citado anteriormente, se puede concluir que la actividad musical durante dichos días abarcó manifestaciones tan distintas como las siguientes: celebraciones litúrgicas (misas, oficios); interpretación de villancicos (de tres de los cuales — realizados para la ocasión por el maestro de capilla tortosino B. Sanz- se recoge la letra); y otras varias funciones promovidas fuera de la catedral, tanto por instituciones religiosas como civiles: procesiones, bailes nocturnos y mascaradas, toques de campanas (con participación de instrumentos de viento "altos"), desfiles militares acompañados de clarines y cajas, espectáculos taurinos, representaciones teatrales - tanto terrestres como fluviales-, etc. En definitiva, el resultado de las celebraciones tortosinas de 1701 fue un espectáculo "inte-

59. La copla es la siguiente:

\author{
"Viva nuestro Monarca, \\ viva mil siglos, \\ gran Rey de las Españas \\ FELIPE el QVINTO”.
}

60. Esta alusión a los timbales que aparece por primera vez junto al clarín pero en un sentido de participación continua ("volvieron a sonar"), hace suponer que con ese nombre el narrador se está refiriendo a lo que anteriormente, en este mismo impreso, ha denominado cajas.

61. Se trata, como se ha ido viendo, de una fiesta típicamente barroca por su carácter de teatro total, global y público, en la que la música, salvo evidentes incompatibilidades, está presente en cada una de las manifestaciones festivas celebradas, bien sea en primer plano, bien como un ingrediente más, o bien como simple fondo sonoro. [Vid. nuevamente: -Gino STEFANI: Musica Barocca. Poetica e ideologia, op. cit.,pp.7-72].

62. Sobre la presencia de bailes y mascaradas como un elemento más de la fiesta barroca en el ámbito hispánico, pueden verse diversos trabajos. De aplicación peninsular, aunque no específicamente musical, cfr.: -José María DíEz BoRQUE: "De los siglos de oro al siglo de las luces", op. cit., pp.207-238. Referidos en concreto al aspecto musical: [como un ejemplo en territorio de la antigua Corona de Aragón:] -Antonio EzQuerro: Villancicos Policorales aragoneses del siglo XVII. Barcelona, CSIC, 2000, pp.12, 20-21, y 161-176 (estas últimas páginas, con inclusión de la transcripción en partitura de una "máscara" —concebida como villancico de Reyes para el año 1654_, obra del compositor Juan de Torres); y [como referencias a la antigua Corona de Castilla:] -Louise K. Stein: "Los músicos de la Capilla Real y la música de los festejos palaciegos, 1590-1648”, en La Capilla Real de los Austrias. Música y ritual de corte en la Europa moderna. S.l., Fundación Carlos de Amberes, 2001, pp.251-275. En cuanto a Latinoamérica, entre otros muchos trabajos, puede consultarsẹ: -Viana CADENAS GARCía: "La vida musical en la Caracas del siglo XVII", op. cit., pp.57-59. Y para Italia: -Gino STEFAnI: Musica barocca..., op. cit., pp.7-72. 
gral", en el que el engalanamiento visual - luminarias, tapices, vestidos extraordinarios, flores, textos poéticos, estandartes bordados, etc.-, incluso olfativo - pólvora, incienso, flores, etc.-, pero muy particularmente, auditivo, supone una de las manifestaciones culturales y artísticas más ricas de la sociedad hispánica, en un modelo de festejos que sería desarrollado, con ligeras variantes, en otras ocasiones similares en otros muchos lugares de los territorios hispánicos, incluida Latinoamérica, e incluso en otros territorios europeos, como los italianos.

$$
* * *
$$

Las conclusiones a que se ha podido llegar, parecen quedar ratificadas por el hecho de que, este impreso, en absoluto constituye un caso único ${ }^{63}$, sino que, antes al contrario, existen otros muchos ejemplares de características similares -y procedentes de lugares más o menos cercanos al propuesto-, los cuales describen festejos realizados con motivo de diferentes acontecimientos reales, tanto del siglo XVII como del XVIII. Por poner algunos ejemplos:

Remontándonos en el tiempo, hallamos una prueba de que la celebración de este tipo de festividades ya era común en el siglo XVII. Precisamente, la encontramos en el impreso de 1649 Pompa festiva y real aparato, que dispuso alegre y executó gozoso el Real Monasterio de S. Lorenço, Octava Maravilla del Mundo. En el recibimiento de la Sereníssima Reyna nuestra Señora Doña Mariana de Austria ${ }^{64}$. En la descripción - realizada por los mismos monjes de dicho monasterio- de tales celebraciones llevadas a cabo durante el reinado de Felipe IV con motivo del recibimiento de su segunda esposa, Mariana de Austria, aparecen varias referencias a la ejecución musical, entre las cuales destaca la siguiente: [con motivo de la entrada del rey y la reina en El Escorial el 9 de octubre] "[...] cantó la capilla el Verso, Te ergo quaesumus y luego el Prior [...] entonó los versos, y oraciones, que manda el Pontifical Romano, a que respondieron la Capilla, la Comunidad, y los quatro órganos, que a todos causó admiración. Siguióse a esta música otra a tres coros, que cantaron con destreza este Villancico [...]"65. En este caso también el texto del villancico en cuestión, policoral, aparece escrito en el impreso que describe las celebraciones.

Un caso de festejos que duraron varios días cercano en el tiempo, aunque celebrado en Barcelona en honor a Carlos II, es el descrito en el impreso también anónimo de 1698, Festivo agradecimiento que por la alegre conclusion de la paz universal de la Monarquia de España, con las demás Coronas y Principes Christianos, rindiò a la Magestad de Dios la Excelentissima Ciudad de Barcelona ${ }^{66}$ Dichos festejos se celebraron con "una alegre, y vistosa Procession, [en la que] cantò la Capilla de los Musicos el Hymno Te Deum laudamus, [...] terciando los Versos con el Organo, y los Menestriles", diversos bai-

63. Aunque resulta ser especialmente interesante por dedicar una atención considerable a la descripción de la participación musical de los festejos.

64. Madrid, Imprenta Real, 1649. [Véase: -Paúl R. LaIRD: "Los villancicos del siglo XVII en el Monasterio del Escorial", en La Música en el Monasterio del Escorial. Actas del Simposium. Madrid, Instituto Escurialense de investigaciones históricas y artísticas, 1992, pp.174-175].

65. Id., p.175.

66. Estas celebraciones festivas no se realizaron durante días consecutivos y se alargaron durante varios meses, empezando el 29 de noviembre de 1697 - con motivo del Decreto de paz del Rey Carlos II, en Madrid - y finalizando el 5 de abril dando paso a la Pascua. Este documento de 1698 fue impreso en Barcelona por Thomàs Loriente, en Casa de Cormellas. [E: Bbc, FB 5922; véase: -Josep Pavia I Simó: La música en Catalunya en el siglo XVIII. Francesc Valls (1671c.-1747). Barcelona, CSIC, 1997, pp.68-69]. 
les, desfiles con timbales, clarines y ministriles, celebraciones litúrgicas con interpretación de villancicos, etc.

En Barcelona también se organizaron diferentes actos festivos en honor a Felipe $\mathbf{V}$, como lo muestra el impreso de 1702, Festivas demonstraciones y magestuosos obsequios, con que el muy lliustre, y Fidelissimo consistorio de los deputados, y oydores del principado de Cataluña, celebrò la dicha que llegò à lograr, con el deseado arribo, y feliz himeneo, de sus catolicos reyes D. Felipe IV. de Aragon, y V. de Castilla, conde de Barcelona, \& y Doña Maria Luisa Gabriela de Saboya, que Dios guarde, prospere, y en su sucession eternize ${ }^{67}$ En este caso, de igual modo que en el de los festejos tortosinos, se celebraron desfiles con presencia de trompetas, timbales y ministriles, hubo ejecuciones de gran variedad de músicos por diferentes lugares de la ciudad (coros de clarines, chirimías...), se interpretaron villancicos y un Te Deum en distintos actos religiosos, hubo representaciones teatrales con presencia de músicos, cantores y actores, etc.

Por otra parte, también se conservan impresos que documentan la existencia de este tipo de celebraciones - promovidas por motivos políticos - en diferentes lugares de latinoamérica. Un ejemplo de las mismas lo encontramos en la Relación de Fray Juan de la Torre, Aclamación festiva de la muy noble Imparial Villa de Potosí, en la digníssima promoción del Excmo. Señor Maestro Don Fray Diego Morzillo, Rubio y Auñóon ${ }^{68}$ que se celebró con motivo de la entrada del Virrey Fray Diego Morzillo en Potosí en 1716. De dicha entrada se conserva, además de un cuadro conmemorativo pintado por Melchor Pérez Holguín $n^{69}$, la loa — de la que se ha conservado tanto el texto como la música— "Guerra, alarma, suenen los clarines", atribuida por Robert Stevenson a Antonio Durán de la Mota, maestro de capilla en la Matriz de Potosi ${ }^{70}$.

Referente nuevamente a Tortosa, también se conserva una publicación similar de 1746, en este caso con motivo de la muerte de Felipe $\mathbf{V}$ y de la coronación de su hijo Fernando VI; se trata de Festivos y leales aplausos con que la Fidelíssima y Exemplar Ciudad de Tortosa celebró la real proclama y levantamiento de los pendones por el rey nuestro señor Don Fernando (que Dios guarde) y en su real nombre $e^{71}$ en los que también hubo una variada participación musical en procesiones, desfiles militares "con sus clarines y timbales", la ejecución de un Te Deum en la catedral, danzantes al son de castañuelas, tamborcillos y dulzainas, etc.

Una vez repasados unos pocos casos aislados, de entre los múltiples posibles, da la impresión de que el caso concreto que se ha venido analizando, aunque ciertamente local, referido a la ciudad de Tortosa (Tarragona), bien podría servir "de aplicación" para otros muchos casos semejantes de la época en los territorios hispánicos (e incluso acaso, en otros muchos lugares europeos: Italia, Francia...). Aceptada la hipótesis anterior, se trataría, por tanto, de un caso "representativo" y quién sabe si incluso "paradigmático", de lo que suspuso la "gran fiesta barroca" (en su sentido de "espectáculo integral", unificador de las diferentes artes y manifestaciones culturales), el cual destaca - y se diferencia en esto de muchos otros documentos de características semejantes-, por su detallada descrip-

67. Barcelona, Imprenta de Rafael Figueró, año 1702.

68. Lima, Francisco Sobrino, 1716. Existe un ejemplar en la Biblioteca Nacional de Lima. [Véase: -Carlos SEOANE y Andrés Eichmann: Lírica Colonial Boliviana. Bolivia, Quipus, 1993, pp.47-48].

69. Conservado actualmente en el Museo de América de Madrid.

70. [Véase: -Carlos Seoane y Andrés EichmanN: op. cit., p.47].

71. Festejos realizados durante los días 7 a 9 de octubre de 1746. Documento impreso en Barcelona por Pablo Nadal. [Arxiu Històric de Les Terres de l'Ebre, Tortosa, R.8852]. 
ción de la presencia musical en los diferentes actos y funciones realizadas con motivo de unas festividades.

Abundando en esta idea, se conocen además y se han estudiado — desde el punto de vista de la participación musical- este tipo de festejos en Londres, París u otros importantes lugares de Europa (Venecia, Roma, Munich, Viena.... $)^{72}$, pero, como se ha visto, la península ibérica no fue en absoluto ajena a ellos. Antes al contrario, este tipo de festejos integrales "como propaganda política" de diferentes monarcas — siglos XVII y XVIII — están documentados, para el caso hispánico, no sólo en Madrid o Barcelona sino, por su expansión geográfica, en casi cualquier lugar de la corona (incluyendo así, desde Tortosa hasta los — para entonces - casi remotos territorios latinoamericanos, alcanzando lugares tan significativos como las ciudades de Lima, México, Bogotá, etc.).

72. Recordemos en este sentido, las célebres fiestas londinenses que tenían lugar en el río Támesis —las cuales, salvando las lógicas distancias, se asemejan a las que hemos podido describir sobre el río Ebro en Tortosa en cuanto a la presencia musical—, cuya música estuvo encargada a G. F. Händel, u otros espectáculos similares en la corte de Versalles, en Nápoles, Viena, Bolonia... [Vid.: -Jenaro Alenda y Mira: Relaciones de Solemnidades y Fiestas Públicas de España. Madrid, Establecimiento Tipográfico "Sucesores de Rivadeneyra", 1903 — fr. especialmente, pp.452-505-. Esta obra, ofrece abundantes ejemplos, tanto españoles como extranjeros, de este tipo de festividades $-\mathrm{y}$ muchas otras - ...]. 